\title{
Social behavior of offspring following prenatal cocaine exposure in rodents: a comparison with prenatal alcohol
}

\author{
Sonya K. Sobrian ${ }^{1}$ and R. R. Holson ${ }^{2}$ \\ 1 Department of Pharmacology, College of Medicine, Howard University, Washington, DC, USA \\ 2 Psychology, New Mexico Institute of Mining and Technology, Socorro, NM, USA
}

\section{Edited by:}

Sheryl Moy, University of North

Carolina, USA

\section{Reviewed by:}

Sandra Kelly, University of South Carolina, USA

Charles V. Vorhees, University of Cincinnati, USA

\section{*Correspondence:}

Sonya K. Sobrian, Department of Pharmacology, College of Medicine, Howard University, 520 West Street, Northwest, Washington, 20059 DC, USA.

e-mail: ssobrian@howard.edu
Clinical and experimental reports suggest that prenatal cocaine exposure (PCE) alters the offsprings' social interactions with caregivers and conspecifics. Children exposed to prenatal cocaine show deficits in caregiver attachment and play behavior. In animal models, a developmental pattern of effects that range from deficits in play and social interaction during adolescence, to aggressive reactions during competition in adulthood is seen. This review will focus primarily on the effects of PCE on social behaviors involving conspecifics in animal models. Social relationships are critical to the developing organism; maternally directed interactions are necessary for initial survival. Juvenile rats deprived of play behavior, one of the earliest forms of non-mother directed social behaviors in rodents, show deficits in learning tasks and sexual competence. Social behavior is inherently complex. Because the emergence of appropriate social skills involves the interplay between various conceptual and biological facets of behavior and social information, it may be a particularly sensitive measure of prenatal insult. The social behavior surveyed include social interactions, play behavior/fighting, scent marking, and aggressive behavior in the offspring, as well as aspects of maternal behavior. The goal is to determine if there is a consensus of results in the literature with respect to PCE and social behaviors, and to discuss discrepant findings in terms of exposure models, the paradigms, and dependent variables, as well as housing conditions, and the sex and age of the offspring at testing. As there is increasing evidence that deficits in social behavior may be sequelae of developmental exposure alcohol, we compare changes in social behaviors reported for prenatal alcohol with those reported for prenatal cocaine. Shortcomings in the both literatures are identified and addressed in an effort to improve the translational value of future experimentation.

Keywords: prenatal cocaine, social interactions, play behavior/fighting, aggression, scent marking, maternal behavior, prenatal alcohol

\section{INTRODUCTION}

Social behavior is inherently complex. The socialization of human beings begins very early and continues throughout the lifespan. Social relationships are critical to the developing organism. Maternally directed interactions are necessary for initial survival, and attachment behaviors in the infant are part of a social behavior system that operates to ensure that the primary caretaker is nearby to protect and nurture the infant (Bowlby, 1988). Theories concerning social development of the child have focused on the mother-infant dyad (Tronick and Cohn, 1989), where the interaction is both the result of the infant's behaviors and the responses of the mother/caretaker to those behaviors. Interacting with one's own infant is reported to be a rewarding and pleasurable experience. This behavior promotes maternalinfant attachments, which ensures optimal care for the developing infant in the face of competing demands (Strathearn et al., 2008).

Play behavior is one of the earliest forms of non-mother directed social behaviors. Children and most other young mammals devote a significant amount of time and energy playing together. Social play is not just a pleasurable activity. It has been suggested that it is an affiliative form of behavior functioning to facilitate social development. Social play is rewarding and serves as a natural reinforcer that is crucial for the development of behavioral flexibility, the acquisition of social communication and cognitive competence, and may function to establish social organization and maintain cohesion in a group, or facilitate the ability to cope with social conflicts (Thor and Holloway, 1984; Pellis and Pellis, 1998; Auger and Olesen, 2009; Trezza et al., 2010). With respect to the sex differences in social play, theories emphasize either social or motor learning functions. In juvenile male non-human primates, social rank correlates with the number of peer social interactions in the form of play fighting (Meaney, 1989). Females spend more time competing for interaction with infants, whereby they acquire the motor skills necessary for handling infants (Meaney, 1989). In general social play behaviors facilitate different aspects of social development which contribute to the acquisition of adaptive social functioning in adulthood (Thor and Holloway, 1984). 


\section{WHILE PLAY DECLINES AS THE CHILD AGES, SOCIAL INTERACTIONS CONTINUE THROUGHOUT THE LIFESPAN}

Social behavior in an adult individual is the result of a complex interaction of genetics, brain development, early childhood experiences pertaining to socialization, and learning throughout the lifespan. These factors combine to affect social cognition and motivation (Kelly et al., 2000).

Moreover, abnormalities in socialization or in the social learning processes can impact social interactions and behaviors throughout the lifespan. Because the emergence of normal appropriate social skills involves the proper interplay between various conceptual and biological facets of behavior and social information, social behaviors may be a particularly sensitive measure of prenatal insult (Chae and Covington, 2009). However, human studies of prenatal insults, especially those involving drugs, are limited in experimental designs available. Animal models afford better control of pre- and peri-natal care, the postnatal environment, nutritional factors, dose and timing of cocaine administration and ploy drug exposure in order to examine behavioral outcomes of prenatal manipulations (Gendle et al., 2004; Chae and Covington, 2009). In addition, they can determine if the maternal-infant interaction is altered by drug-induced changes in the behavior of the offspring. The use of experimental crossfostering, where offspring from 1 litter is given to an unrelated dam from a different (control) treatment group, typically at birth, allows for the successful empirical dissection of maternal versus pup effects (see Wolf et al., 2011 for review). The impact of environmental factors can also be assessed by housing postweaning offspring in enriched, impoverished or standard caging conditions. These various rearing environments can facilitate the examination of simple social processes and establish more clearly the degree to which the changes in social behavior are the direct result of cocaine-induced changes. Moreover, social behavior in rats has been shown to follow similar principles as in humans, and is also a function of genetics, teratogenic influences, early maternal-infant interactions, and later social learning (Kelly et al., 2000). This review will focus primarily on the effects of prenatal cocaine on social behaviors involving conspecifics in rodent models; the effects of developmental alcohol exposure on these behaviors is included as a control. The social behaviors reviewed include social interaction, play fighting/solicitation, and aggressive behaviors, as well as maternal care, maternal aggression, and mother-infant communication. Sexual behavior was not included as it does not parallel the variables in the clinical articles included in this volume.

\section{PRENATAL COCAINE AND SOCIAL BEHAVIOR}

A significant body of literature published during the past 25 years has identified effects of prenatal cocaine exposure (PCE) on growth and development in children. PCE has been shown to influence the ontogeny of motor, cognitive, social skills, and emotional behaviors. Both dose- and gender-specific effects have been identified following PCE, with social behaviors more likely disrupted in boys prenatally exposed to higher levels of cocaine (Delaney-Black et al., 1998; Tronick et al., 2005). Although effects are small, they are first evident in the neonate, remain throughout early childhood, and have been documented in adolescents
(Chae and Covington, 2009). The magnitude of the effects may be masked, in part, by confounding factors in study designs. Most children reported in studies in the literature come from low-income backgrounds and consequently have been exposed to multiple medical and social risk factors associated with long-term poverty, that include poor prenatal care, peri-natal complications, and impoverished parenting styles. The fact that exposure to multiple risk factors has compromising effects on children's outcomes may overshadow any specific effects of PCE (Rodning et al., 1989; Tronick and Beeghly, 1999). Moreover, clinical studies involving drugs of abuse often entail exposure to drugs other than the one of interest, and as a result behavioral alterations may reflect insults other than those due to the specific action of cocaine.

Despite the exponential increase in the number of experimental studies published since the 1980s on the effects of PCE, only a small percentage have focused on social behaviors. Rodents are most often used, with rats being the preferred species; mice were used in only two of the studies discussed (Hahn et al., 2000; Estelles et al., 2005). We did not find published studies of PCE and social behavior that used primates or other mammalian species. While the focus of this review is on prenatal exposure, several studies with combined prenatal-postnatal (lactational) exposure, as well as those in which cocaine was administered to pre-weaning rats or females prior to mating have been included (see Table $\mathbf{1}$ ).

Although the number of studies is limited, there are trends in the data that suggest reliable effects of developmental exposure to cocaine for individual categories of social behavior. Table 1 summarizes these findings collapsed across both species; exposure period and housing conditions are indicated. When not specified, cocaine was administered prenatally to rat dams and animals were raised in a standard housing environment. Detailed summaries of results are provided in the following text. These will be preceded by a brief review of the relevance of the behavior, and pertinent clinical findings.

\section{PRENATAL COCAINE AND MATERNAL BEHAVIORS}

Maternal substance abuse has been associated with deficits in parental functioning. Mothers recovering from cocaine addiction experience difficulties in their maternal roles as care givers, and are described as more passive and disengaged in interactions with their newborns than non-drug-using mothers (see Johnson et al., 2002 for review). It is possible that some of these deficits in maternal care are influenced by the state-traits of PCE infant; these infants are frequently irritable and hyper-aroused by environmental stimuli, responses which might elicit less care and establish a cycle of passivity in which the caretaker becomes more and more passive in attempts at interaction (Chasnoff et al., 1987). Maternal interaction with their young children continue to be problematic, as exemplified by reduced mother-child play interactions and increased hostility toward the child (see Febo and Ferris, 2007 for review).

Although frequently associated with poor parenting outcomes, maternal drug use is not always related to deficits in parenting skills. No differences between cocaine-using and comparison mothers were noted in sensitivity, social-emotional and cognitive growth fostering, and response to infant distress on a 
Table 1 | Effects of developmental cocaine exposure on maternal behaviors in dams and first generation offspring compared to controls.

\begin{tabular}{|c|c|c|c|}
\hline Behavior & Enhanced & No effect & Impaired/reduced \\
\hline $\begin{array}{l}\text { Maternal care } \\
\text { ( } F_{0} \text { dams) }\end{array}$ & $\begin{array}{l}2 \\
\text { Peeke et al. (1994; pre-mating, gestational, } \\
\text { and lactational cocaine: PPD 1-20) } \\
\text { Nephew and Febo (2010; pre-mating cocaine: } \\
\text { PPD 2) }\end{array}$ & $\begin{array}{l}9 \\
\text { Johns et al. (2005; PPD } 5 \text { or 10) } \\
\text { Nelson et al. (1998; PPD 3) } \\
\text { Sobrian et al. (1990; 1995; PPD 1) } \\
\text { Heyser et al. (1992; PPD 2, 5-9) } \\
\text { Tonkiss et al. (1995; pre-mating and } \\
\text { gestational cocaine: PPD 2-12) } \\
\text { McMurray et al. (2008a; PPD } 8 \text { and 12) } \\
\text { Nephew and Febo (2010; pre-mating } \\
\text { cocaine: PPD } 9 \text { and 16) }\end{array}$ & $\begin{array}{l}8 \\
\text { Johns et al. (1994b; 2005; PPD 1) } \\
\text { Nelson et al. (1998; PPD 1) } \\
\text { Kinsley et al. (1994; PPD 1-2) } \\
\text { McMurray et al. (2008a; IC: ges- } \\
\text { tational and lactational: PPD 8) }\end{array}$ \\
\hline $\begin{array}{l}\text { Acute cocaine } \\
\left(F_{0} \text { dams }\right)\end{array}$ & & $\begin{array}{l}\text { Vernotica et al. (1996; single acute } \\
\text { cocaine injection PPD 1, testing: } 16 \mathrm{~h} \\
\text { later) }\end{array}$ & $\begin{array}{l}\text { Vernotica et al. (1996; single acute } \\
\text { cocaine injection PPD 1. Testing: } 4 \\
\text { hrs later) } \\
\text { Kinsley et al. (1994; single acute } \\
\text { cocaine injection on PPD 5-6) }\end{array}$ \\
\hline $\begin{array}{l}\text { Intergenerational } \\
\text { effects ( } F_{1} \\
\text { offspring) }\end{array}$ & $\begin{array}{l}\mathbf{1} \\
\text { McMurray et al. (2008a; IC: gestational and } \\
\text { lactational: PND } 60 \text { mated; tested at PPD 8) }\end{array}$ & $\begin{array}{l}2 \\
\text { Johns et al. (2005; adult mated; tested } \\
\text { at PPD } 5 \text { or 10) } \\
\text { Johns et al. (2007; tested at PND 28: } \\
\text { Pup-induced retrieval-M and F) }\end{array}$ & $\begin{array}{l}3 \\
\text { Johns et al. (2005; adult mated; } \\
\text { tested at PPD 1) } \\
\text { Johns et al. (2007; PND 60: M) } \\
\text { McMurray et al. (2008a; PND } 60 \\
\text { mated; tested at PPD 8) }\end{array}$ \\
\hline $\begin{array}{l}\text { Maternal } \\
\text { aggression ( } F_{0} \\
\text { dams) }\end{array}$ & $\begin{array}{l}8 \\
\text { Heyser et al. (1992; PPD 10) } \\
\text { Johns et al. (1997; PPD 6) } \\
\text { Johns et al. (1998a,b; PPD 6, 8, } \\
\text { and 10) } \\
\text { Lubin et al. (2001; PPD 2, 3, and 5) } \\
\text { Johns et al. (2010; PPD 31-35) } \\
\text { Nephew and Febo (2010; pre-mating cocaine: } \\
\text { PPD 2) }\end{array}$ & $\begin{array}{l}\mathbf{1} \\
\text { McMurray et al. (2008a; CC: PPD8 and } \\
\text { CC and IC: PPD 12) }\end{array}$ & $\begin{array}{l}\mathbf{1} \\
\text { McMurray et al. (2008a; IC: PPD8) }\end{array}$ \\
\hline $\begin{array}{l}\text { Mother-infant } \\
\text { communication } \\
\text { (ultrasonic } \\
\text { vocalizations) }\end{array}$ & $\begin{array}{l}\mathbf{1} \\
\text { Hahn et al. (2000; M and F; mice: BALB/cJ } \\
\text { and DBA/2J: tested at PND 2-4) }\end{array}$ & $\begin{array}{l}4 \\
\text { Meyer et al. (1992; M and F; tested at } \\
\text { PND 11) and Hahn et al. (2000); M and } \\
\text { F; mice: SLJ/J: tested at PND 2-4) } \\
\text { Barron and Gilbertson (2005) (M and F; } \\
\text { neonatal cocaine: PND 4-10. Tested at } \\
\text { PND 14) } \\
\text { Barron et al. (2000; M and F; Neonatal } \\
\text { cocaine: PND 4-10. Tested at PND 14) }\end{array}$ & $\begin{array}{l}\mathbf{1} \\
\text { Hahn et al. (2000; M and F; mice: } \\
\text { BALB/cJ and DBA/2J. Tested at } \\
\text { PND 2-4) }\end{array}$ \\
\hline
\end{tabular}

Numbers in bold refer to number of findings for each outcome. Unless otherwise stipulated, cocaine exposure is gestational, and subjects are rats. PND: postnatal day at which ultrasonic vocalization was tested; PPD: postpartum day on which maternal behavior was tested; CC: chronic cocaine during gestation; IC: intermittent cocaine during gestation and lactation; $F_{1}$ : first generation dams. $F=$ females; $M=$ males.

measure of maternal behavior during infant feeding (Neuspiel et al., 1991), or maternal responsivity during free-play (Black et al., 1993). In explaining the impact of prenatal cocaine use on the mother-child parenting outcomes, confounding factors such as maternal psychological functioning and socioeconomic resources must be considered (Jeremy and Bernstein, 1984; Sood et al., 2005). These factors alone or in combination with maternal substance abuse may better explain the impact of prenatal drug use on mother-child relationship outcomes. Moreover, women who use cocaine during pregnancy often continue drug use after delivery, and postnatal maternal substance use is also associated with a number of environmental risk factors that may impact parent-child interactions (Johnson et al., 2002). 


\section{Maternal care}

Poly drug use and other confounding factors in human cocaine abusers (i.e., the availability of prenatal care, socioeconomic status, and environmental conditions in the home) have promoted the use of animal models in which these variables can be more easily controlled. Maternal care behavior has been well characterized in rat models. Female rats show little interest in infants of their own species until shortly before parturition. Approximately $24 \mathrm{~h}$ prior to delivery, they show an intense interest in pups from other litters with nest building, retrieval, grooming, and defense of the young. These behaviors persist through lactation and then abate with weaning (Winslow and Insel, 2002). Moreover, individual variations in key behaviors have been linked to alterations in offspring development (Insel, 2003; Sousa et al., 2006). In general, early care giving experiences can influence the subsequent maternal behavior, stress-susceptibility, and emotionality of the offspring (Sousa et al., 2006; Strathearn and Mayes, 2010).

Environmental insults can give rise to disruptions in motherpup interactions, and such disruptions of the social milieu can influence behavioral development and brain function of the offspring independent of any direct effect of the drug (Tonkiss et al., 1995). Maternal behavior in rats is a complex interplay of hormonal milieu of the dam and the behavior of both the pup and dam. Disruption of the behavior in the maternal-pup dyad is known to have a critical impact on the long-term outcome of the pup and in particular on the socio-emotional behavior of the pup (Meaney, 2001). As in humans, alterations in early maternalinfant interactions may occur because of drug-induced behavioral abnormalities in either or both the rodent pup and/or the mother, resulting in altered dynamics of the maternal-infant interaction (Kelly et al., 2000).

Exposure of the dams to cocaine, either prior to or during gestation and/or during lactation alters maternal care of infants (Table 1). This effect is short lived, and does not require multiple daily cocaine doses. Following daily gestational cocaine exposure, Johns et al. (1994b, 2005) found impaired maternal behavior on postpartum day (PPD) 1 but not PPDs 5 or 10; Nelson et al. (1998) found similar effects on PPD 1 but not 3 . However, intermittent cocaine exposure during both gestation and lactation extends the impairment in maternal behavior until PPD 8 (McMurray et al., 2008a). Moreover, Vernotica et al. (1996) reported that a single postnatal cocaine injection on PPD 1 impaired maternal behavior $4 \mathrm{~h}$ but not $16 \mathrm{~h}$ later. Similarly, Kinsley et al. (1994) saw a shortterm decrement in maternal behavior on PPD 5 or 6 following a single cocaine injection.

Enhanced maternal behavior has been reported in two studies, both of which involved pre-mating cocaine exposure. Peeke et al. (1994), who dosed dams with cocaine 21 days prior to mating, as well as throughout gestation and for 2 weeks postpartum, reported that exposed dams spent more time nursing throughout lactation. However, enhanced maternal behavior was seen only on PPD 2 but not PPD 9 or 16 with only a 10-day pre-mating exposure (Nephew and Febo, 2010).

Developmental cocaine exposure failed to affect maternal behavior in nine studies. This lack of effect is seen primarily following gestational cocaine exposure alone (Sobrian et al., 1990, 1995; Heyser et al., 1992; Nelson et al., 1998; Johns et al., 2005;
McMurray et al., 2008a), and is evident during both early (Sobrian et al., 1990, 1995; Tonkiss et al., 1995; Vernotica et al., 1996; Nelson et al., 1998), and mid (Heyser et al., 1992; Tonkiss et al., 1995; Johns et al., 2005; McMurray et al., 2008a) lactation.

Intergenerational effects of gestational cocaine exposure on the maternal behavior have been assessed in the female offspring of dams exposed to cocaine during pregnancy (first generation dams: $F_{1}$ ). Gestational exposure to cocaine either impaired (Johns et al., 2005; McMurray et al., 2008a) or had not effect on (Johns et al., 2005) the maternal behavior of $F_{1}$ dams. In the Johns et al. (2005) study, the direction of the change was the same for the $F_{1}$ dams as those reported for their $F_{0}$ mothers. In contrast, with the McMurray et al. (2008a) study, it was the $F_{1}$ dams of the chronic gestational cocaine $F_{0}$ dams that showed an impairment, an effect not seen in the original dams. In contrast, $F_{1}$ dams, whose mothers were exposed to intermittent cocaine during both gestation and lactation, showed enhanced maternal care of their pups.

In a similar study, first generation adolescent and young adult offspring were exposed to pups to induce maternal behavior (Johns et al., 2007). When testing occurred at PND 28, gestational cocaine exposure did not impair male or female juveniles' interactions with 1- to 5-day-old pups (Johns et al., 2007). Subsequently however, 60-day-old male rats did display impaired maternal care of neonates (Johns et al., 2007; females were not tested on PND 60). Taken together, these studies indicate that the effects of developmental cocaine exposure are intergenerational, at least for some aspects of maternal behavior. Clearly, it is an intriguing finding that deserves more study.

\section{Maternal aggression}

Interacting with one's own infant is reported to be a rewarding and pleasurable experience, which promotes maternal-infant attachments, and ensures optimal care for the developing infant in the face of competing demands (Strathearn and Mayes, 2010). However, cocaine abuse is highly correlated with maternal neglect and poorer maternal-infant interactions; mothers who are addicted to cocaine appear to be not only less appropriately responsive to their infants, but also find these interactions less rewarding and stress provoking, a situation which may engender child neglect and abuse (Mayes et al., 1997). It has also been reported that in their interactions with young children, drug-using mothers are less likely to use positive reinforcement and more likely to threaten physical discipline than non-drug-using mothers (Johnson et al., 2002). Moreover, there is a higher incidence of foster care placements and allegations of physical abuse, sexual abuse, and neglect among cocaine-exposed 2 year olds compared with non-drug-exposed 2 year olds (Wasserman and Leventhal, 1993).

Maternal aggression has been defined as a subset of maternal behaviors in mammals that is aimed at intruders into the postparturient female's nest area or at those threatening her young (Blanchard et al., 2003). In rat, both offensive and defensive aggressive behaviors have been well characterized (Sousa et al., 2006). While maternal aggressive behavior is generally considered adaptive, excessive, or mal-adaptive attacks can result in injury to pups (Lubin et al., 2001). Maternal aggression can be elicited 48-24 h prior to birth; it peaks during the first 10 PPD (McMurray et al., 
2008a), and drops off sharply in the hours following pup removal (Blanchard et al., 2003).

Cocaine has been reported to disrupt various aspect of maternal behavior, including maternal aggression. Table 1 lists the effects of chronic and intermittent cocaine during gestation alone or in combination with postnatal lactational exposure on intruder-induced maternal aggression in dams $\left(F_{0}\right)$ and their first generation $\left(F_{1}\right)$ female offspring. The resident/intruder paradigm was used in all seven studies.

Heyser et al. (1992) reported that cocaine-treated dams raising their own offspring were quicker to initiate the first attack on a female intruder at PPD 10. While a similar increase was seen in controls dams, only cocaine-treated females exhibited an increased number of aggressive attacks against the female intruder throughout the testing period. The lack of sustained aggression reported in cocaine-exposed dams rearing cross-fostered normal pups suggested that characteristics of the PCE-pups may contribute to the treatment-induced increase in maternal aggression (Heyser et al., 1992). However, is should be noted that dams exposed to cocaine during pregnancy did not differ from control dams in pup retrieval latency, nest building behavior, time spent in the nest, or time spent suckling pups (Heyser et al., 1992).

Increased aggression was also reported in cocaine-exposed dams tested early in postpartum period. At PPD 6, these females exhibited an increase in threats and attacks toward an intruder, behavior that did not reflect withdrawal from cocaine; increased aggression was seen in dams whose cocaine treatment ended on gestational day 20, and dams who received cocaine throughout lactation (PPD 1-20; Johns et al., 1997). Similar increases in maternal aggression were reported on PPD 6, 8, and 10 for dams treated chronically with cocaine during gestation (Johns et al., 1998a). This increase was hypothesized to reflect altered sensory or perceptual systems that caused stimuli to be viewed as more threatening than they are (Johns et al., 1998a).

When tested during the initial postpartum period at PPD 2, 3 , and 5, gestational cocaine exposure produced a non-dosedependent increase in the duration of the attacks on the male intruder but not fight attack behavior, in general (Lubin et al., 2001). All dams rearing their natural litters exhibited increased aggressive behavior as evidenced by a decreased latency to pin an intruder. The authors suggest that the aggressive behavior seen in this early postpartum period is not as robust as seen during midlactation (Lubin et al., 2001). However, pre-mating exposure of the female to cocaine produces an increased aggressive response to a male intruder at PPD 2 (Nephew and Febo, 2010). Female rats sensitized to cocaine within the 2 -week period prior to mating exhibited shorter attack latencies and an increased frequency and duration of attacks on PPD 2, but not on PPD 9, suggesting that in contrast to gestational exposure which produces more aggressive behavior from the dams at mid-lactation, the effects of pre-mating cocaine are more robust almost immediately after birth. This increase in maternal aggression was attributed to a possible cross-sensitization between cocaine and the natural reward of maternal care (Nephew and Febo, 2010). At PPD 8, gestational exposure to chronic cocaine (CC) failed to alter defensive or aggressive behaviors in the dams, while dams exposed to intermittent gestational and lactational cocaine (IC) were less aggressive toward a male intruder (McMurray et al., 2008a). However, rearing conditions altered aggressive behavior in IC dams, who exhibited increased threat to a small male intruder only when rearing their biological litter. No significant differences were found in any group on PND 12.

As with maternal behavior, intergenerational effects have been reported for maternal aggression. However, rearing conditions $\left(F_{0}\right.$ dam treatment) rather than prenatal exposure history have been shown to impact the aggressive responses of first generation $\left(F_{1}\right)$ dams. All $F_{1}$ dams raised by either CC or IC $F_{0}$ dams displayed increased maternal aggression toward a small male intruder when tested on PPD 8; moreover, IC-reared $F_{1}$ dams exhibited increases in more aspects of aggressive behavior and threatened intruders more often (McMurray et al., 2008a). These data suggest that $F_{0}$ dam treatment, rather than prenatal exposure condition of the litter appears to be the more salient intergenerational factor influencing maternal aggression.

In summary, clearly prenatal exposure to cocaine increases maternal aggression in the resident/intruder paradigm, irrespective of the sex of the intruder. Factors that influence this effect include not only prenatal treatment, but also the postpartum age at testing, and whether the dam is rearing her biological or foster litter. Increased aggression against an intruder has been reliably reported to occur on PPD 2-6; reports of its occurrence on PPD 8, 9, and 10 are mixed, while it is absent at PPDs 12 and 16. There is some suggestion that the effects of PCE on maternal aggression are more robust during mid-gestation. In contrast the reverse is seen following pre-mating cocaine. There is also evidence of intergenerational effects of developmental cocaine exposure on maternal aggression. $F_{1}$ dams appear to exhibit higher levels of aggressive behavior than their $F_{0}$ dams; as with $F_{1}$ dams, this behavior is influenced by PCE and rearing conditions.

\section{Maternal-infant communication}

Crying is a universal vocalization in human infants, as well as in the infants of other mammals. It represents an early evolutionary adaptation for maternal contact and sustenance of an infant, where the need to re-establish mother-infant contact is essential for infant survival when contact is lost (Newman, 2007). Human infants prenatally exposed to cocaine show more passive-withdrawn negative engagement (Tronick et al., 2005), and are reported to produce fewer and shorter cries (Hahn et al., 2000).

In rodents, auditory signals produced by pups play an important role in the regulation of the mother-infant relationship. The ultrasonic vocalizations (USV) emitted by neonatal rats and mice are a critical aspect of pup behavior upon separation from the dam (Kelly et al., 2009a). The frequency of ultrasonic calling is a measure of separation distress, which increases with increasing amounts of separation, and reliably elicits maternal search and retrieval behavior. Moreover, call length and call frequency communicate information about individual identity, as well as the age and gender of the caller (Hahn et al., 2000). As USVs have been shown to promote lactation by increasing prolactin release, and also reduce maternal biting and cannibalism (Barron and Gilbertson, 2005), alterations in USVs can negatively impact pup survival. 
Table 1 summarizes the results of four studies that investigated the characteristics of USVs after developmental exposure to cocaine. In $F_{1}$ mice of three different genotypes, alterations in the call characteristics of USV reflected an interaction between gestational drug exposure and genotype. Overall, PCE influenced two call characteristic of USV on PNDs 2-4: the rate of calling was reduced in two strains, while there was an increase of the beginning pitch of calls in the same two strains. However, pups of one genotype were unaffected by PCE (Hahn et al., 2000). These cocaine effects, though reliable, were small and differences in USVs were strongly influenced by mouse genotype. In a rat model, PCE failed to alter the frequency of isolation-induced USV in male and female offspring at PND 11, while acute exposure prior to testing markedly suppressed this behavior (Meyer et al., 1992). Postnatal cocaine exposure had an effect similar to that seen with PCE. When tested on PND 14, exposure to cocaine on PNDs 4-10 had no effect on either the frequency of vocalization (Barron et al., 2000) or the sonographic waveform analysis in either male or female offspring (Barron and Gilbertson, 2005). Sex differences were not observed in any of the studies.

In summary, neither chronic pre- nor post-natal exposure to cocaine altered isolation-induced USVs in rat. In mice, the direction of the effect following prenatal cocaine was genotype dependent, with a decreased frequency seen in two of the three strains tested. In addition to species differences, it should be noted that the production of USVs decreases with increasing age (Barron and Gilbertson, 2005) and the lack of an effect in older pups could represent a floor effect. However, the fact that acute cocaine prior to testing markedly suppressed USVs at PND 14 (Meyer et al., 1992) does not support this hypothesis. Despite the small number of studies, it would appear that species differences rather than exposure window, i.e., prenatal or postnatal, has the greater influence on the effects of developmental cocaine exposure on USVs.

\section{SOCIAL INTERACTIONS}

The necessity of social interactions for normal development has been outlined above. Infants and young children prenatally exposed to cocaine are somewhat aggressive, show poorer social attachment, and display abnormal play behavior in unstructured environments (Chasnoff et al., 1987; Oro and Dixon, 1987). Social interactions are also an important aspect of a rodent's life. They include all sexual and reproductive activities (although these are not be covered in this review), as well as aggressive behavior.

Social interactions are highly complex functions, requiring recruitment of and interaction between multiple neural circuits, with endocrine hormones and pheromonal cues playing a significant role in their coordination and execution (Sousa et al., 2006). This aspect of social behavior differs from play in that it continues throughout the life of the animal.

We have been able to locate four separate studies of gestational cocaine effects on social investigation, with six findings that are presented in Table 2. Estelles et al. (2005) assessed social investigation in adult male mice exposed prenatally to cocaine. Following weaning, subjects were reared either in isolation or in an enriched, multiple-animal environment. Animals were placed for $10 \mathrm{~min}$ in an open field with an unfamiliar test male; group-reared males showed enhanced social investigation of strangers, while males raised in isolation investigated strangers less than controls.

The remaining three studies utilized rats. Following PCE, Johns and Noonan (1995) tested male offspring at PND 90, and females at PND 60. Single subjects were placed in an open field with two unfamiliar subjects of the same sex for $10 \mathrm{~min}$. Frequency, duration and latency of eight social behaviors were measured. Hence there were 24 behavioral measures per sex. Cocaine-exposed females showed an increased frequency of rough grooming, with no changes on the other 23 variables; males showed increased latency to reciprocate contact, with no changes on the other 23 variables. To what degree these single differences constitute anything more than statistical noise is not clear.

Neugebauer et al. (2004) tested only female offspring exposed to gestational cocaine. On the assumption that female cycling would confound results, all females were ovariectomized prior to testing. Again, pups were reared in either social (enriched) or isolation conditions. Animals were tested on three daily $10 \mathrm{~min}$ tests starting at each of three ages (PND 62, 90, and 122). Test animals were exposed to a single novel stranger. Four behavioral variables [play solicitations (see Play), follows, mutual sniffs, and mutual rears] were measured. Gestational exposure to cocaine increased mutual sniffs and mutual rears in both rearing conditions.

Finally, Overstreet et al. (2000) cross-fostered male and female cocaine-exposed pups to non-treated dams at birth. Pairs of rats of the same sex and treatment condition were tested for $5 \mathrm{~min}$ on PNDs 30, 60, and 120 days. Total time spent on social interactions was assessed. Results were the same across sexes: males and females exposed to gestational cocaine interacted less on PNDs 30 and 120, but did not differ from controls on PND 60.

Clearly, these findings do not provide evidence for any strong effect of gestational cocaine exposure on subsequent social investigation in offspring. Half the findings report enhanced social investigation, and half report precisely the opposite outcome. Neither sex, species, nor testing paradigms provide any obvious resolution for these disparate results. However, these studies do indicate that social investigation is sensitive to gestational cocaine.

\section{PLAY}

Play behavior is essential for the normal development of social skills. PCE has been associated with deficits in this social behavior. Toddlers exposed to cocaine in utero were found to differ from controls on measures of attachment and play behavior, and as young children they were somewhat aggressive, showed poor social attachment and displayed abnormal play behavior in unstructured environments (Oro and Dixon, 1987). These drug-exposed children experienced no distress in response to separation from caregivers, did not seek close physical contact, and appeared to show no strong feelings of pleasure or distress. They were unwilling to combine toys and fantasy play, and exhibited decreased representational play. Elements of their play behavior were characterized by the investigators as a soft neurological sign (Rodning et al., 1989; Howard et al., 1990).

Juvenile rats engage in a distinctive form of interactive social behavior commonly referred to as social play, play fighting, or play chasing that is readily observed in pairs or larger groups, and differs from other forms of social activities. Juvenile social 
Table 2 | Effects of developmental cocaine exposure on social behaviors in offspring compared to controls.

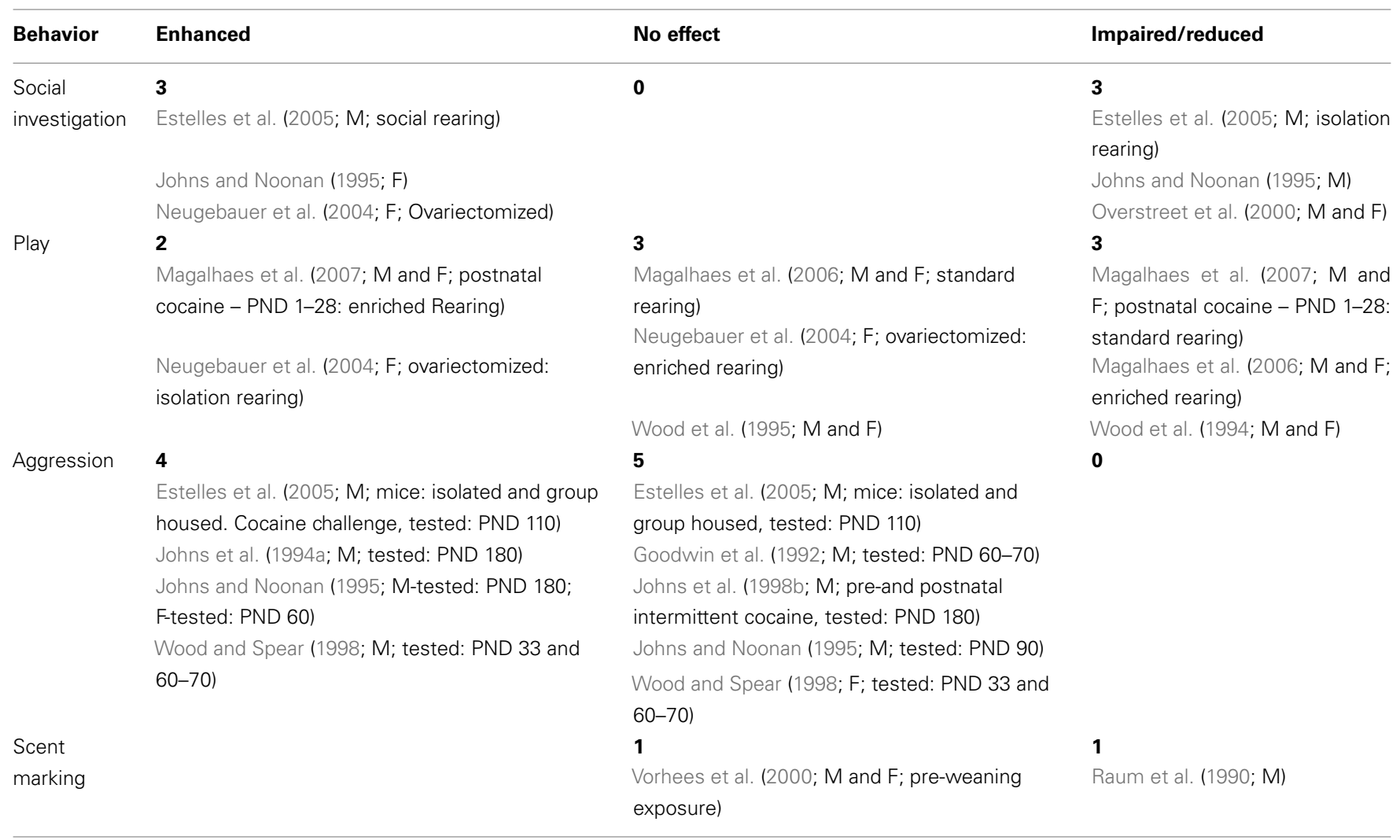

Numbers in bold refer to number of findings for each outcome. Unless otherwise stipulated, cocaine exposure is gestational and subjects are rats. $M$, male; $F$ female; PND, postnatal day.

play behavior (JSPB) is well characterized in the rat, and consists of a flurry of chasing, pouncing, tumbling, and wrestling movements which often terminates after one juvenile assumes a dominance stance over an inverted juvenile partner (i.e., pinning). JSPB occurs mainly before sexual maturity, peaking at a midpoint of the periadolescent period. Although JSPB is sexually dimorphic, with males exhibiting higher levels of social play than females, due to increased rates of play initiation, there are only minor differences in the sequential organization of play. The early social environment can influence JSPB, in that increased maternal grooming can reduce later juvenile social play and vice versa (Thor and Holloway, 1984; Pellis and Pellis, 1998; Magalhaes et al., 2007; Auger and Olesen, 2009).

Table 2 lists the five studies that involved play behavior; rats were used in all studies and cocaine was administered prenatally in all but one (Magalhaes et al., 2007). In an initial study by Wood et al. (1994), both male and female PCE offspring showed play deficits. Both sexes exhibited less pinning during social play, and were pinned more by their same sex-partner. The submissive behavior exhibited by PCE offspring was thought to reflect changes in the animals' overall ability to respond appropriately in play or social situations. In a second study by these investigators (Wood et al., 1995), adolescent play behaviors (pinning and pouncing) were unaffected by exposure to foot-shock, forced swim or white noise stress, suggesting that stress might have normalized play behavior in PCE offspring. However, alterations in play behavior were manifested by the way in which other animals played with cocaine-exposed animals; play partners were more hesitant to initiate and less likely to continue play with PCE adolescents. This latter finding was interpreted as decreased attractiveness of the PCE offspring to conspecifics.

Environmental conditions have been identified as a confounding variable in clinical studies of PCE (van Gelder et al., 2010). A third study reported that environmental manipulations attenuate the behavioral effects of prenatal cocaine on play behaviors (Neugebauer et al., 2004). While rearing in an impoverished environment increased play solicitations in prenatal PCE offspring at PND 60, 90, and 120, those raised in enriched conditions did not differ from controls. Magalhaes et al. (2006) reported that rearing PCE offspring in a standard environment (SE) had no effect on play fighting, solicitation, or social investigation. In contrast, rearing in an enriched environment (EE) decreased both play behavior and social investigation in offspring prenatally exposed to cocaine. This reduction was attributed to the preference of EE-reared animals to explore a novel environment instead of engaging in social play, and to improved social memory in the PCE rats.

These investigators evaluated the effects of EE in rats exposed to cocaine during the first 28 days of postnatal life (Magalhaes et al., 2007). Again, environmental rearing condition interacted with developmental cocaine exposure. However, in contrast to PCE 
offspring, animals postnatally exposed to cocaine and reared in a SE showed a decreased frequency of play solicitation, while those reared in the EE displayed more invitation to play and comfort behaviors, as well as a decrease in social investigation. The increase in play solicitation suggested that the rearing in an EE enhances the attractiveness of the play partner. An increased display of comfort behavior (i.e., social groom and pile-up behavior) was interpreted as a stress-reducing strategy in a novel environment, while the decrease in social investigation exhibited by postnatal cocaine rats reared in an EE again suggested improved social memory.

The results of these five studies suggest that PCE either impairs or has no effect on play behaviors; outcome differences are seen despite the similarity in dependent variables across studies.

Enhanced play behavior reflects an interaction of the rearing environment and developmental period of cocaine exposure, and is seen only with postnatal cocaine exposure. In both PCE and postnatally exposed cocaine offspring, rearing in an EE appears to improve social memory.

\section{AGGRESSION}

While aggressiveness per se is not considered abnormal in humans, abnormal aggression has been linked to psychiatric conditions and is seen as a symptom rather than a disorder of its own (see Haller and Kruk, 2006 for a review). Despite the underlying pathology, aggressive behavior is a social, economic, and medical issue (Blanchard et al., 2003).

Childhood aggression can be a serious problem, as such children are more likely to be involved in future juvenile delinquency. Prenatal exposure to cocaine may contribute a risk factor for aggressive behavior problems. Infants born to mothers who used cocaine during pregnancy are characterized as fussy/difficult, unadaptable, and exhibit signs of increased irritability (Chasnoff et al., 1987). There are also reports of increasing externalization problems (aggression, delinquency) in children who were prenatally exposed to cocaine, some as early as 3 years of age (Griffith et al., 1994; Delaney-Black et al., 2000; Richardson et al., 2009), although there are findings to the contrary (Accornero et al., 2002; Bennett et al., 2002).

The expression of aggressive behavior appears to be modulated not only by child-related variables, such as altered emotional regulation and impulse control (Bendersky and Lewis, 1998a,b), but also by increased environmental and maternal risk factors (Bendersky et al., 2006). Women who use cocaine have higher rates of depression and have been found to be less responsive in interactions with their children (Wood et al., 1995; Mayes et al., 1997). Maternal harsh discipline and greater caregiver psychological distress have also been associated with increased behavioral problems in children (Bennett et al., 2002; Minnes et al., 2010). Moreover the lower economic and educational status of the most likely single head of household can create a chaotic living environment that increases the risk of aggression through poor parenting and variables involved in living in marginalized neighborhoods. However, it should be noted that prenatal cocaine-exposed children in adoptive or foster care are rated as having more behavioral problems than those living with maternal or relative caregivers (Linares et al., 2006).
The contribution of the male gender and age to displays of aggressive behavior following PCE has been consistently reported (see Delaney-Black et al., 2000; Anderson and Bushman, 2002; Bendersky et al., 2006 for reviews), although there are reports that girls between 4 and 10 years of age show increased rates of delinquency (Minnes et al., 2010), and higher aggression scores (Sood et al., 2005). While PCE disposes pre-teens to aggressive behavior (Delaney-Black et al., 1998; Bendersky et al., 2006; Linares et al., 2006), social provocation of adolescent or young adult males exposed to heavy/persistent prenatal cocaine is associated with greater escape behavior, inferring greater submission, social withdrawal, or anxiety as opposed to aggressive behavior (Greenwald et al., 2011).

Aggressive behavior in animals is used to establish social hierarchies and to defend territories. Pre-clinical research has provided a detailed description of aggression and defense patterns in rodents. Although components of aggression are similar, patterns of aggressive behavior are usually distinctive in males and females. The identification of target sites for attack, and the motivational antecedents of attack behavior have allowed for the analyses of offensive and defensive aggression strategies and for the use of these maneuvers in maternal behavior (see Blanchard et al., 2003 for review).

Six experimental studies are summarized in Table 2 . All except one used rats (Estelles et al., 2005). While all used chronic gestational cocaine exposure, two also used intermittent prenatal exposure alone (Johns et al., 1994a, 1998b), and Johns et al. (1998b) used combined intermittent pre and postnatal cocaine exposure. Several paradigms have been used to study aggressive behavior: resident-intruder (Goodwin et al., 1992; Johns et al., 1994a; Johns and Noonan, 1995; Estelles et al., 2005), shock-elicited aggression (Goodwin et al., 1992), and water competition (Wood and Spear, 1998). Although males are most often used for investigating aggressive behavior, three studies tested both male and female offspring (Johns and Noonan, 1995; Johns et al., 1998b; Wood and Spear, 1998).

In mice (Estelles et al., 2005) PCE had no effect on offensive (i.e., attack latency and number) or defensive (i.e., threat, avoidance/flee) aggressive behaviors in adult (PND 110) offspring reared in groups or in isolation. In contrast, housing conditions impacted aggression scores following cocaine challenge. While isolated PCE animals exhibited an increase in defensive aggression, groups housed PCE males were clearly more aggressive, exhibiting increases in both defensive and offensive aggressive behavior.

Rearing conditions have also been shown to exert modest but detectable influence on aggressive behavior. Using a shock-elicited design, Goodwin et al. (1992) reported that prenatal cocaine per se did not influence aggressive behavior in adulthood. Irrespective of prenatal treatment exposure, both fostered and non-fostered young adult male offspring, PND 60-70, raised by cocaine-treated dams were more aggressive, exhibiting shorter attack latencies, with no effect on the number of fighting episodes. Moreover, in contrast to mice, no aggression was observed in any offspring in the resident/intruder model.

A series of studies by Johns et al. (1994a, 1998b), Johns and Noonan (1995) investigated the effects of daily or intermittent PCE alone or in combination with postnatal intermittent exposure on 
aggressive behaviors in male offspring in a resident/intruder paradigm. In all studies, litters were cross-fostered to untreated surrogate dams. Following daily gestational cocaine exposure, male offspring tested at PND 180 exhibited increased duration of circle threat to a male intruder (Johns et al., 1994a). In a similar study (Johns and Noonan, 1995), at PND 180 chronic PCE male offspring tested for aggression exhibited an increased frequency and duration, and decreased latency to chase a male intruder. At PND 90, PCE did not alter any of the 11 measures of aggression scored. Rough grooming can be considered as social interaction or mild aggression. PCE female offspring at PND 60 showed an increase in this behavior toward non-exposed females. However, while intermittent gestational cocaine did not significantly affect aggressive behavior in either male or female pups at PND 30 and 60, combined intermittent gestational and postnatal cocaine increased the incidence and duration, and decreased the latency of PCE males to chase an intruder (Johns et al., 1998b).

Adolescent and young adult rats were tested for aggression in a water competition task (Wood and Spear, 1998). At PND 33, there was an increased incidence of attacks by PCE males, but not females. As young adults, offspring between PND 60-70, again on PCE males engaged in more incidences of boxing during water competition. In contrast, the incidence of attacks exhibited by PCE female offspring did not differ from control females at either.

In summary, these studies suggest that aggressive behavior in PCE rats may be sensitive to the same factors the influence this behavior in humans: age, gender, and environmental rearing/housing conditions. Consistent increases in aggressive behaviors are seen in PCE male rats with increasing age, and while the studies testing females are very limited, it would appear that mild aggression may be present earlier than in males. In humans, the results of a recent laboratory simulation of an aggressive situation, indicates that teenage males show escape/avoidance behavior rather than aggression when presented with a choice (Greenwald et al., 2011). Although aggressive behavior is more often reported in male children following PCE, it is possible that a more subtle or defensive form of aggression is evidenced by females (see Maternal Aggression).

\section{SCENT MARKING}

Urinary scent marks have ethologically important roles in social communication among conspecifics in many rodent species. Scent marking behavior is a communication tool for maintaining social relationships in both sexes; however, males mark two to three times more than females (Raum et al., 1990). When deposited in the environment, scent marks convey information on territory ownership in the absent of the owner, social status, as well as reproductive, health, and nutritional status, and enable recognition of individuals. Among males, scent marking and the counter-marking of the scent marks of other males are important components of dominance advertisement, especially among male mice, and strongly influence their aggressive interactions (see Arakawa et al., 2008 for recent review).

In adulthood, prenatal cocaine-exposed males, but not females, exhibited significantly less marking behavior than controls. Males also exhibited demasculinization in some sexual behaviors (Raum et al., 1990). In contrast, pre-weaning exposure to cocaine failed to alter scent marking behavior in PND 80 rats of either sex. Moreover, typical gender differences were seen, with males marking two to three times more than females (Vorhees et al., 2000). Although cocaine alters scent marking behavior in rats, the effect may be function of the developmental exposure period.

\section{SUMMARY}

Prenatal cocaine exposure clearly exerts an immediate, short-term negative effect on maternal care of offspring. This finding has important methodological implications. Given the demonstrated long-term effects of abnormal maternal care seen in first generation male and female offspring, such drug-induced impairments confound direct and indirect effects on exposed pups. Presumably these behavioral changes in dams can be parceled out by cross-fostering pups to drug-naive dams at birth. Such crossfostering should be a common technique until/unless it can be demonstrated that these drug-induced changes in early postnatal maternal care have no long-term effects on offspring.

A consistent finding is that cocaine exposure enhances maternal aggression toward unfamiliar intruders, for more than a week after the final gestational cocaine exposure. Effects are intergenerational, with first generation dams also exhibiting increased maternal aggression. Whether this enhanced aggression is due to drug-induced increases in anxiety/fearfulness or increased combativeness remains to be elucidated.

Finally, a variety of other behaviors appear to be sensitive to developmental cocaine exposure, in that the majority of studies report changes of some kind. Yet the direction of these changes is currently unclear. Thus reported developmental cocaine effects on infant vocalizations, play, social investigation, and scent marking are more or less evenly divided between reports of no effects, enhanced, or diminished/impaired effects. The commonality of such mixed results clearly provides a major challenge to experimenters. Collectively, the above findings provide evidence for clear species or sex differences; the one exception is offspring aggression.

\section{MECHANISTIC CONSIDERATIONS: OXYTOCIN AND ARGININE-VASOPRESSIN \\ Oxytocin}

Evidence from several decades of animal research indicated that the neuropeptides oxytocin (OT) and arginine-vasopressin (AVP) have substantial roles in regulating complex social behaviors and social cognition. Oxytocin (OT), a nine amino acid peptide, is synthesized primarily in magnocellular neurons of the hypothalamus, and is released directly into the bloodstream from the posterior pituitary. Its function on both peripheral reproductive tissue and in the central nervous system (CNS) is now well characterized. As a neurosecretory hormone on reproductive tissue, OT plays a critical role in the onset of parturition and milk ejection during lactation. In the CNS, it is not only responsible for the induction of maternal nurturing behavior, but also for modulating social cognition, and affiliative behavior in both sexes (see Ross and Young, 2009 for review).

Animal studies indicate a role for OT in mediating maternal behavior in rodents and alloparental care in prairie voles, motherinfant bonding in sheep and pup-mother interactions in rodents, social (pair) bonding adult in adult voles, and social recognition 
in adult rodents. Pharmacological manipulations with exogenous OT, OT antagonists, and antisera indicate that OT plays a more important role in regulating the onset of maternal behavior than in the maintenance of maternal behavior in rat (Fahrbach et al., 1985; van Leengoed et al., 1987). Genetic experiments using OT and OT receptor (OTR) knock out (KO) mice support pharmacological findings in rat of the role of OT in regulating maternal behavior (Nishimori et al., 1996; Young et al., 1996). OTKO mice were more likely to display infanticidal behavior than wild-type mice housed in a social semi-natural environment (Ragnauth et al., 2005), while OTRKO mice are more deficient in maternal behavior than peptide-KO mice (Tankayanagi et al., 2005). There is also evidence that transgenerational transmission of maternal behavior may be mediated by changes in OTR expression (Francis et al., 1999, 2002).

Prairie vole juveniles and some adult females display nurturing behavior toward pups that are not their own. There is evidence that OT may play an important role in this alloparental behavior (Ross and Young, 2009). OTR density in the nucleus accumbens (NAc) is significantly correlated with the display of alloparental behavior in both juvenile and adult virgin females (Olazabal and Young, 2006), and injections of an OT antagonist into the NAc block the expression of maternal-like behavior toward pups in adult females.

There is some evidence in rodents that OT also modulates the pup's response to the mother. OTKO and OTRKO mouse pups emit fewer USV following separation from their dams than their wild-type counterparts (Winslow et al., 2000; Tankayanagi et al., 2005). OT also influences the attraction of the pup to their dam, as OT antagonist blocks the preference for maternal odors in pups at 15 days of age (Nelson and Pankseep, 1996).

Social recognition, which allows social species to distinguish familiar conspecifics from strangers and to remember individuals previously encountered, is necessary for successful group living and survival. While central injections of OT have been shown to enhance the time that a male rat remembers a conspecific (see Choleris et al., 2009 for review), OTR antagonists do not block memory performance. However, while wild-type mice habituate to familiar mice, OTKO males fail to habituate after repeated exposures to the same mouse (Ferguson et al., 2000).

There is a growing body of literature suggesting that in humans OT modulates social perception, social cognition, and social behavior, all of which promote social approach and affiliation (see Heinrichs et al., 2009; Lee et al., 2009 for reviews). Pharmacological studies have suggested that OT is also able to enhance human social cognition (see Heinrichs et al., 2009), a finding that is consistent with the role of OT in social recognition in rodents. Intranasal OT improved identity recognition for neutral and angry faces (Savaskan et al., 2008) and during game play, stimulated behavior consistent with enhanced interpersonal trust which is a prerequisite of social affiliation and social approach in humans (Kosfeld et al., 2005).

Data involving the role of OT in human interpersonal relationships is scarce and inconclusive. However, active maternal behavior during the first trimester and the first postpartum month has been correlated with high plasma concentration of OT (Feldman et al., 2007; Galbally et al., 2011). OT in humans has been associated with both an enhanced ability to interact socially (Nelson and Pankseep, 1996), and a better central control of stress and anxiety in social situations (Kavaliers et al., 2003).

\section{Arginine-vasopressin}

Arginine-vasopressin is similar in structure to OT. It is also synthesized in the hypothalamus and released into the bloodstream via the posterior pituitary gland. Like OT, numerous animal studies have also implicated AVP in mating, pair bonding, and adultinfant attachment (Lim and Young, 2006). Whereas OT is involved in the regulation of social approach behavior, social affiliation, and attachment, AVP has primarily been implicated in male-typical social behaviors, including aggression, pair-bond formation, scent marking, and courtship (see Choleris et al., 2009; Heinrichs et al., 2009 for reviews).

In male rats, social recognition of a juvenile conspecific is enhanced by peripheral administration of AVP immediately after exposure (Sekiguchi et al., 1991; Freeberg et al., 1999), and is reversed by an AVP antagonist (Dantzer et al., 1987). Unlike OT, however, AVP appears to play a more important role in social recognition in males than in females. While AVP improves social recognition in both sexes, AVP antagonists impair social memory only in males (Blunthe and Dantzer, 1990). Two AVP receptors in the CNS, V1aR, and V1bR, have been implicated in species and sex differences in social behavior (Donaldson and Young, 2008). While male V1aR KO mice are completely impaired in social recognition, V1bR KO mice, while impaired with respect to WT mice, can distinguish between familiar and unfamiliar conspecifics (Wersinger et al., 2004). Moreover, AVP V1a receptor antagonist selectively blocks aggressive behavior in hamsters (Ferris et al., 2006), and there appears to be an association between Avpr-1a receptor gene and partner preference in the male prairie vole (Young and Wang, 2004).

The few studies conducted on the role of AVP in human social behavior suggest behavioral effects similar to those found in animals. In subjects with personality disorders, the positive correlation found between levels of AVP in cerebrospinal fluid and life histories of general aggression was suggested as reflecting an enhancing effect of central AVP in individuals with impulsive aggressive behavior (Coccaro et al., 1998). As has been reported in animal studies, intranasal AVP influences social communication in a sex-specific manner. In men, AVP stimulated agonistic responses to faces of unfamiliar men, while in women the neuropeptide produced affiliative responses to unfamiliar female faces (Thompson et al., 2006). In addition, the Avpr-1a seems to be associated with differences in altruistic or prosocial behavior in men and women, and with pair bonding and marital satisfaction in men (Walum et al., 2008).

\section{Prenatal cocaine, maternal behavior, and oxytocin}

In lactating rats, maternal aggression serves to protect the nesting environment from intruders. Administration of oxytocin directly into the central nucleus of the amygdala $(\mathrm{CeA})$ or the bed nucleus of the stria terminalis of the lactating rat has been shown to decrease maternal aggression during the postpartum period (Consiglio et al., 2005). In contrast, the infusion of an OT antagonist into the CeA increases maternal aggression to the point that it is not 
adaptive (Lubin et al., 2003). The role of OT in maternal behavior following gestational cocaine treatment has focused on aggressive behavior in lactating dams. Research, primarily from Johns et al. (1994b, 1997, 1998a, 2004), indicate that chronic exposure to cocaine throughout gestation (i.e., GD 1-20) results in decreased levels of OT, up-regulation of the oxytocin receptor binding density, and decreased receptor affinity in the amygdala, that coincide with significant increases in maternal aggression on PPD 6 (Johns et al., 1994b, 1997, 1998a, 2004; Elliott et al., 2001). However, during the early postpartum period (i.e., PPD 2), gestational exposure to cocaine resulted in an increase in oxytocin mRNA in the paraventricular nucleus, without an effect on receptor binding (McMurray et al., 2008b). Increased maternal aggression has also been reported at PPD 2 following gestational (Lubin et al., 2001) and pre-mating (Nephew and Febo, 2010) cocaine exposure. Prenatal cocaine-induced disruptions in the onset of maternal behavior have been correlated with decreased levels of OT in the ventral tegmental area (VTA), the medial pre-optic area, and the hippocampus (Johns et al., 1997; Jarrett et al., 2006). The intergenerational effects of PCE that have been reported for maternal aggressive behavior have also been seen for OT. First generation dams also had lower levels of OT in the amygdala (McMurray et al., 2008a), but in contrast to their dams, only a strong trend for increased mRNA was found in the supraoptic nucleus (McMurray et al., 2008b). It would therefore appear that gestational cocaine exposure induces wide-spread alterations in OT system dynamics that may mediate heightened maternal aggression in rat during the postpartum period. We are unaware of published studies involving the effects of PCE on vasopressin.

With respect to the possible mechanism that underlies gestational cocaine's effect on OT and postpartum maternal aggression, there is some suggestion that dynamic changes in serotonergic (5HT) and/or dopaminergic (DA) system may be involved (Johns et al., 2004). Brain structures involved in maternal behavior or aggression, such as the paraventricular nucleus, hippocampus, amygdala, and the VTA contain both OT neurons fibers and/or receptors, as well as DA and 5-HT projections and receptors. Anatomical evidence indicates that OT neurons are in close contact or have synaptic connections with DA and 5-HT neurons, and that OT system dynamics are altered by cocaine and manipulation of these two transmitter systems. Moreover, the fact that pup retrieval and a nursing posture over pups is blocked in parturient dams by infusion of an OT antagonist into either the VTA or the medial preoptic area highlights the interaction between DA neurons and OT pathways in maternal behavior (see Johns et al., 2004; McMurray et al., 2008b, and Strathearn and Mayes, 2010 for reviews).

\section{DEVELOPMENTAL ETHANOL EXPOSURE AND SOCIAL BEHAVIOR}

Evidence linking gestational alcohol exposure in humans to social defects, including a range of misbehaviors, is subject to high levels of confounding variables. Not surprisingly, women who drink during pregnancy in modern industrialized nations differ on a large variety of factors from those who do not. These confounds necessitate independent validation of a biological linkage between social deficits and developmental alcohol exposure in animal models, which provide satisfactory control of the many confounds plaguing human research. Although animal research is still very limited, this review will show that developmental alcohol exposure does indeed impact a range of rodent social behaviors. These data will be compared to findings reviewed with animal models of developmental cocaine exposure to determine whether the effects on social behaviors produced by cocaine exposure are of the same general nature and magnitude as those reported for alcohol-exposed animals.

\section{DEVELOPMENTAL ETHANOL EXPOSURE IN HUMANS}

Gestational exposure to alcohol is doubtlessly as old as human consumption of alcoholic beverages, yet it is only in the past halfcentury that fetal alcohol syndrome (FAS), which occurs in 0.3-2.2 per 1,000 live births in the US (Ripabelli et al., 2006) and is the consequence of heavy drinking during pregnancy, has been identified and characterized. More recently, concern has shifted to the question of the effects the on brain and behavior of the prevalent use of lower levels of drinking during pregnancy, ethanol intake levels below those required for FAS. It is now recognized that prenatal alcohol exposure may produce a broader spectrum of defects, now recognized as fetal alcohol spectrum disorders (FASD; Jones et al., 2010). Infants affected by FASD show not only intellectual impairment, and difficulties in learning, memory, problem-solving, and attention, but also experience additional problems with mental health and social interactions (Ripabelli et al., 2006). These social disorders are variously characterized as conduct disorder, externalizing disorders, or antisocial personality disorder, and have in common a higher level of misbehavior, delinquency, and even criminal conduct. For simplicity, this variety of misbehaviors will discussed under the term "externalizing disorder," realizing that in actuality there can be subtle differences between these various terms.

\section{Evidence for ethanol-induced externalizing disorders in humans}

A number of studies have provided evidence for linkages between externalizing disorders, as defined above, and mild (Sood et al., 2001; Sayal et al., 2007), moderate (Olson et al., 1997), and high (Mattson and Riley, 2000; D'Onofrio et al., 2007; Disney et al., 2008) levels of gestational alcohol intake. Although these studies have attempted to control for a variety of common confounds (Schuckit et al., 2003; Huizink and Mulder, 2006; McGee and Riley, 2007) it is unlikely that they have been able to either identify or control for all sources. Despite these uncertainties, results of some studies have already suggested that it is these confounds and not developmental alcohol exposure per se which account for subsequent externalizing behaviors in exposed offspring (e.g., Hill et al., 2000).

\section{DEVELOPMENTAL ETHANOL EXPOSURE IN ANIMALS}

We have identified 19 published peer-reviewed studies that have investigated a range of social behaviors following developmental exposure, i.e., gestational, postnatal, or combined exposure to ethanol. Of these 19 studies, 16 used rats (Barron and Riley, 1985; Meyer and Riley, 1986; Royalty, 1990; Blanchard and Hannigan, 1994; Kelly and Dillingham, 1994; Wilson et al., 1996; Lugo et al., 2003, 2006; Lawrence et al., 2008; Kelly et al., 2009b; Hamilton et al., 2010; Mooney and Varlinskaya, 2011) and three used mice (Kršiak et al., 1977; Ewart and Cutler, 1979; Hale et al., 1992). There 
were no studies of primates or other mammalian species. Further, of these 19 studies, 8 exclusively used gestational exposure (Kršiak et al., 1977; Barron and Riley, 1985; Meyer and Riley, 1986; Ness and Franchina, 1990; Royalty, 1990; Hale et al., 1992; Blanchard and Hannigan, 1994; Hamilton et al., 2010), three used exclusively postnatal exposure (Kelly and Dillingham, 1994; Wilson et al., 1996; Wellmann et al., 2010), and the remaining eight studies combined gestational and postnatal exposure (Ewart and Cutler, 1979; Tattoli et al., 2001; Marino et al., 2002; Lugo et al., 2003, 2006; Lawrence et al., 2008; Kelly et al., 2009b; Mooney and Varlinskaya, 2011). There are too few comparable studies within these various exposure periods to allow meaningful comparisons across developmental exposure periods for individual social behavior categories. Consequently studies were collapsed across both species and exposure periods, to get a first approximation of alcohol exposure effects on social behaviors. These 19 studies looked at six different social behaviors; outcomes were reviewed by behavior and summarized in Table 3.

\section{Maternal behavior}

Three studies in rats have reported reductions in maternal response to neonates following either gestational (Barron and
Riley, 1985; Ness and Franchina, 1990) or postnatal exposure (Wilson et al., 1996). These reductions were seen both at an early age (Barron and Riley, 1985; Ness and Franchina, 1990; Wilson et al., 1996) and in adults (Barron and Riley, 1985), and in young rats of both sexes (Barron and Riley, 1985; Ness and Franchina, 1990). In contrast, Marino et al. (2002) reported no effects of combined pre- and postnatal ethanol exposure on the maternal response to neonates. Four studies with three different ethanol exposure periods do not allow strong conclusions, especially in the presence of one negative report. However, the suggestion is clearly that ethanol exposure over a wide developmental range may impair simple pup retrieval behaviors.

\section{Play}

The results for play behavior are contradictory. There are two reports of unchanged behavior (Blanchard and Hannigan, 1994; Mooney and Varlinskaya, 2011), four of enhanced play behavior (Meyer and Riley, 1986; Royalty, 1990; Lawrence et al., 2008; Hamilton et al., 2010) and two of reduced play following developmental exposure (Meyer and Riley, 1986; Mooney and Varlinskaya, 2011). Again, as shown in Table 3, these various behavioral outcomes do not segregate by sex; all three possible outcomes are

Table 3 | Social behavior in rodents exposed developmentally to ethanol compared to controls.

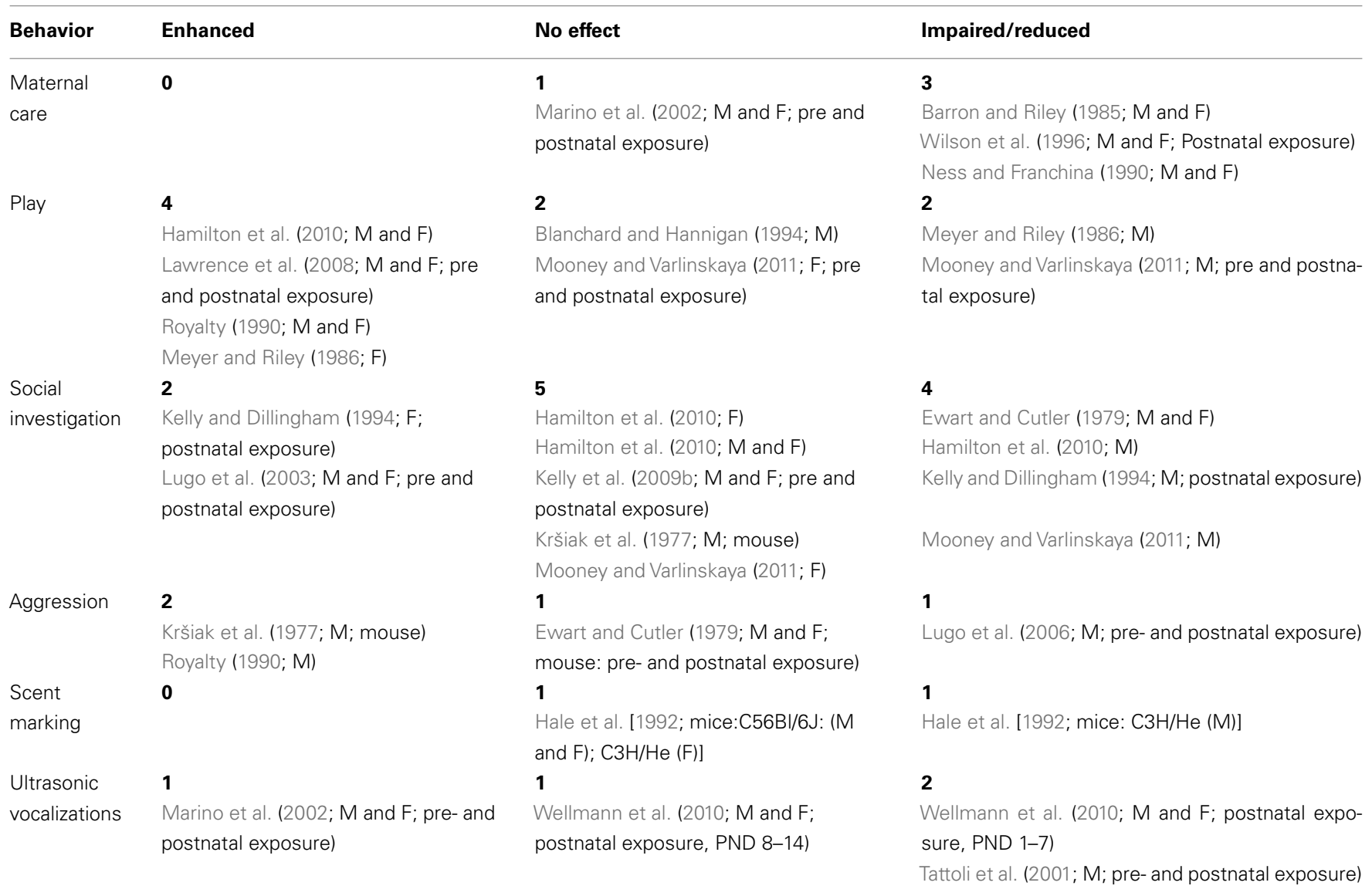

Numbers in bold refer to number of findings. Unless otherwise stipulated, alcohol exposure is gestational and subjects are rats. F, females; $M$, males; PND, postnatal day. 
seen in both sexes, across studies. The increase in play behavior may reflect an enhanced responsiveness to stimulation related to social experiences as a consequence of developmental alcohol exposure (Hamilton et al., 2010). Moreover, alterations in the normal sexually dimorphic patterns of play behavior (Meyer and Riley, 1986) are suggestive of masculinization of females (increased play) and demasculinization of males (decreased play) as a consequence of developmental alcohol exposure. This finding agrees with hormonal and morphological studies suggesting that gestational alcohol can masculinize females and demasculinize males (McGivern et al., 1984; Barron et al., 1988).

\section{Social investigation}

Social investigation is the behavioral variable most often measured. However, the results do not provide strong evidence for effects of developmental alcohol in either direction, or on one sex more than the other. Two studies report increases in social investigation (Kelly and Dillingham, 1994; Lugo et al., 2003). Of these two, Kelly and Dillingham (1994) study again suggested that developmental ethanol exposure demasculinizes males and defeminizes females. In contrast, five studies found no changes in social investigation, in one but not both sexes. Hamilton et al. (2010) reported that males but not females show reduced social investigation; however, after $24 \mathrm{~h}$ of social isolation neither sex showed changes in social investigation. Similar results were reported in three other studies (Kršiak et al., 1977; Kelly et al., 2009b; Mooney and Varlinskaya, 2011). Finally, four studies reported reductions in social investigation by one or both sexes (Ewart and Cutler, 1979; Kelly and Dillingham, 1994; Hamilton et al., 2010; Mooney and Varlinskaya, 2011).

\section{Aggression}

Given the possible link between gestational alcohol exposure and externalizing disorders in humans, it is surprising that so few studies have investigated aggression in rodents following developmental exposure to alcohol. As with play and social investigation, these studies have variously reported increases, (Kršiak et al., 1977; Royalty, 1990), decreases (Lugo et al., 2006), and no change (Ewart and Cutler, 1979) in aggressive behavior, with both the increased and the decreased aggression reported in males.

\section{Scent marking}

A single study of scent marking in mice (Hale et al., 1992) found that gestational effects were strain- and sex-dependent. Gestational ethanol had no effect on the scent marking of either sex in the $\mathrm{C} 56 \mathrm{Bl} / 6 \mathrm{~J}$ strain, but reduced male but not female scent marking in the $\mathrm{C} 3 \mathrm{H} / \mathrm{He}$ strain.

\section{Summary}

Overall, 11 studies reported no effects of developmental ethanol exposure, 9 found increases and 13 found reductions or impairment of some measure of social behavior (Table 3 ). These results do not appear to differ by sex, age at exposure or species, nor did any one type of social behavior stand out as producing a clear developmental ethanol behavioral effect in a single direction. Additional research, including within-laboratory replication, is required, as this research area has been woefully neglected.
However, a plurality of studies (22 of 33) do show some change in social behavior following developmental alcohol exposure, and at the very least suggest that developmental alcohol exposure has some, as yet uncharacterized, impact upon rodent social behaviors. Further, five of the above studies report some degree of sex difference in developmental alcohol effects upon social behaviors (Meyer and Riley, 1986; Hale et al., 1992; Kelly and Dillingham, 1994; Hamilton et al., 2010; Mooney and Varlinskaya, 2011). Such findings combine with the known sex differences in social behaviors to make imperative the inclusion of both sexes in all future studies.

\section{COMPARISON/CONCLUSION}

The clinical literature indicates that in humans, prenatal and/or postnatal exposure to either alcohol or cocaine is associated with what we have referred to as externalizing disorders in the offspring, disorders characterized by abnormalities in social behavior. However, such findings are necessarily entangled in a number of confounding factors, which can be addressed in animal studies. While this review has concentrated on the impact of PCE on rodent social behaviors, it has also surveyed findings of developmental ethanol effects on social behaviors.

In comparing these two sets of literature, it is somewhat surprising that for neither substance of abuse has there been a major effort to determine effects of prenatal exposure on measures of social behavior in rodents or any other species. Our inability to characterize the impacts of these substances on social behaviors reflects in part this relative paucity of studies.

With few exceptions, both literatures are marked by a lack of consistent effects. In many cases, results are divided almost evenly between reports of no effects, increases and decreases on a variety of social behaviors as a consequence of prenatal/developmental exposure to cocaine or ethanol. This lack of unanimity also makes it difficult to reliably characterize the effects of either compound on the range of rodent social behaviors surveyed.

Establishing a phenotype of social behavior following developmental exposure to cocaine or alcohol is imperative. It is therefore necessary that future research concentrates on successful withinand between-laboratory replication of results. With exception of Johns and colleagues, even deliberate within-laboratory replication has not been attempted in either arena. Ultimately, only experimental replication will succeed in unraveling the current confusion of reported results. Here it is important to note that failures to replicate are by no means limited to the fields reviewed herein. True within-laboratory replicate experimental design is simply unheard of in the vast bulk of animal research. Until funding agencies and investigators understand replicate design and analysis, and are forced to utilize such designs, much rodent research will continue to be as fundamentally flawed as the studies reviewed here.

A second conclusion relates to methodological issues. The cocaine literature in this area has been marked by an unusually careful attempt to identify and address the confounds found not only in clinical but also in animal research. Thus, unlike the ethanol literature reviewed here, researchers investigating developmental cocaine effects have begun to identify and control for the effects of this drug that are mediated by the behavioral impact 
of drug exposure on the maternal-neonatal unit. As we have seen, researchers have clearly established that cocaine directly impairs maternal care of offspring, and increases maternal aggression. In view of these findings, it is imperative that future designs using gestational exposure cross-foster offspring to drug-naive dams. Equally, it is also important to characterize the effects of such impaired maternal care on the pups. Such attempts are currently under way (e.g., Johns and colleagues), and are very much encouraged. Since it is also not unlikely that alcohol exposure will impair

\section{REFERENCES}

Accornero, V. H., Morrow, C. E., Bandstra, E. S., Johnson, A. L., and Anthony, J. C. (2002). Behavioral outcome of preschoolers exposed prenatally to cocaine: role of maternal behavioral health. J. Pediatr. Psychol. 27, 259-269.

Anderson, C., and Bushman, B. (2002). Human aggression. Annu. Rev. Psychol. 53, 27-51.

Arakawa, H., Blanchard, D. C., Arakawa, K., Dunlap, C., and Blanchard, R. J. (2008). Scent marking behavior as an odorant communication in mice. Neurosci. Biobehav. Rev. 32, 1236-1248.

Auger, A., and Olesen, K. (2009). Brain sex differences and the organization of juvenile social play behavior. $J$. Neuroendocrinol. 21, 519-525.

Barron, S., and Gilbertson, R. (2005). Neonatal ethanol exposure but not neonatal cocaine selectively reduces specific isolation-induced vocalization waveforms in rats. Behav. Genet. 35, 93-102.

Barron, S., and Riley, E. P. (1985). Pupinduced maternal behavior in adult and juvenile rats exposed to alcohol prenatally. Alcohol. Clin. Exp. Res. 9, 360-365.

Barron, S., Segar, T. M., Yahr, J. S., Baseheart, B. J., and Willford, J. A. (2000). The effects of neonatal ethanol and/or cocaine exposure on isolation-induced ultrasonic vocalizations. Pharmacol. Biochem. Behav. $67,1-9$.

Barron, S., Tiernan, S. B., and Riley, E. P. (1988). Effects of prenatal alcohol exposure on the sexually dimorphic nucleus of the preoptic area of the hypothalamus in male and female rats. Alcohol. Clin. Exp. Res. 12, 59-64.

Bendersky, M., Bennett, D., and Lewis, M. (2006). Aggression at age 5 as a function of prenatal exposure to cocaine, gender, and environmental risk. J. Pediatr. Psychol. 31, 71-84.

Bendersky, M., and Lewis, M. (1998a). Prenatal cocaine exposure and impulse control at two years. Ann. N. Y. Acad. Sci. 84, 365-367.
Bendersky, M., and Lewis, M. (1998b). Arousal modulation in cocaineexposed infants. Dev. Psychol. 34, 555-564.

Bennett, D. S., Bendersky, M., and Lewis, M. (2002). Children's intellectual and emotional-behavioral adjustment at 4 years as a function of cocaine exposure, maternal characteristics, and environmental risk. Dev. Psychol. 38, 648-658.

Black, M. M., Schuler, M., and Nair, P. (1993). Prenatal drug exposure: neuro-developmental outcome and parenting environment. J. Pediatr. Psychol. 18, 605-620.

Blanchard, B. A., and Hannigan, J. H. (1994). Prenatal ethanol exposure: effects on androgen and nonandrogen dependent behaviors and on gonadal development in male rats. Neurotoxicol. Teratol. 16, 31-39.

Blanchard, R. J., Wall, P. M., and Blanchard, D. C. (2003). Problems in the study of rodent aggression. Horm. Behav. 44, 161-170.

Blunthe, R. M., and Dantzer, R. (1990). Social recognition does not involve vasopressinergic neurotransmission in female rats. Brain Res. 535, 310-304.

Bowlby, J. (1988). Developmental psychiatry comes of age. Am. J. Psychiatry 145, 1-10.

Chae, S., and Covington, C. (2009). Biobehavioral outcomes in adolescents and young adults prenatally exposed to cocaine: evidence from animal models. Biol. Res. Nurs. 10, 318-330.

Chasnoff, I. J., Burns, K. A., and Burns, W. J. (1987). Cocaine use in pregnancy: perinatal morbidity and mortality. Neurotoxicol. Teratol. 9, 291-293.

Choleris, E., Clipperton-Allen, A. E., Phan, A., and Kavaliers, M. (2009). Neuroendocrinology of social information processing in rats and mice. Front. Neuroendrocrinol. 30, 442-459.

Coccaro, E. F., Kavoussi, R. J., Hauger, R. L., Cooper, T. B., and Ferris, C. F. (1998). Cerebrisounal fluid vasopressin levels: correlates with aggression and serotonin function

maternal care of pups, the ethanol research clearly needs to adopt the same approach.

To summarize, increased research, replication of results, and research which controls for confounding of direct drug effects and effects mediated by abnormalities in the mother-pup unit is necessary. With the implementation of the above suggestions, it will be possible to successfully characterize the impact of these common drugs of abuse on the social behavior of rodents, and by extension perhaps humans as well.

in personality-disordered subjects. Arch. Gen. Psychiatry 55, 708-714.

Consiglio, A. R., Borsoi, A., Pereira, G. A., and Lucion, A. B. (2005). Effects of oxyticun microinjected into the central amygdaloid nucleus and bed nucleus of stria terminalis on maternal aggression behavior in rats. Physiol. Behav. 85, 354-362.

Dantzer, R., Blunthe, R. M., Koob, G. F., and Le Moal, M. (1987). Modulation of social memory in male rats by neurohypophyseal peptides. Psychopharmacology 91, 363-368.

Delaney-Black, V., Covington, C., Templin, T., Ager, J., Martier, S., and Sokol, R. (1998). Prenatal cocaine exposure and child behavior. Pediatrics 102, 945-950.

Delaney-Black, V., Covington, C., Templin, T., Ager, J., Nordstrom-Klee, B., Martier, S., Leddick, L., Czerwinski, R. H., and Sokol, R. J. (2000). Teacher-assessed behavior of children prenatally exposed to cocaine. Pediatrics 106, 782-791.

Disney, E. R., Iacono, W., McGue, M., Tully, E., and Legrand, L. (2008). Strengthening the case: prenatal alcohol exposure is associated with increased risk for conduct disorder. Pediatrics 122, e1225-e1230.

Donaldson, Z. R., and Young, L. J. (2008). Oxytocin vasopressin and the neurogenetics of sociality. Science 322, 900-904.

D’Onofrio, B. M., Van Hulle, C. A., Waldman, I. D., Rodgers, J. L., Rathouz, P. J., Lahey, M., and Benjamin, B. (2007). Causal inferences regarding prenatal alcohol exposure and childhood externalizing problems. Arch. Gen. Psychiatry 64, 1296-1304.

Elliott, J. C., Lubin, D. A., Walker, C. H., and Johns, J. M. (2001). Acute cocaine alters oxytocin levels in the medial preoptic area and amygdale in lactating rat dams: implications for cocaine-induced changes in maternal behavior and mater aggression. Neuropeptides 35, 127-134.

Estelles, J., Rodriguez-Arias, M., Maldonado, C., Aguilar, M., and Minarro, J. (2005). Prenatal cocaine exposure alters spontaneous and cocaine-induced motor and social behaviors. Neurotoxicol. Teratol. 27, 449-457.

Ewart, F. G., and Cutler, M. G. (1979). Effect of ethyl alcohol on development and social behaviour in the offspring of laboratory mice. Psychopharmacology 62, 247-251.

Fahrbach, S. E., Morrell, J. I., and Pfaff, D. W. (1985). Possible role of endogenous oyxtocin in estrogenfacilitated maternal behavior in rats. Neuorendocrinology 40, 526-532.

Febo, M., and Ferris, C. F. (2007). Development of cocaine sensitization before pregnancy affects subsequent maternal retrieval of pups and prefrontal cortical activity during nursing. Neuroscience 148 , 400-412.

Feldman, R., Weller, A., ZagoorySharon, O., and Levine, A. (2007) Evidence for a neuroendocrinological foundation of human affiliation: plasma oxytocin levels across pregnancy and the postpartum period predict mother-infant bonding. Psychol. Sci. 18, 965-970.

Ferguson, J. N., Young, L. J., Hearn, E. F., Matzuk, M. M., Insel, T. R., and Winslow, J. T. (2000). Social amnesia in mice lacking the oxytocin gene. Nat. Genet. 25, 284-288.

Ferris, C. F., Lu, S. F., Messenger, T., Guillon, C. D., Heindel, N., Miller, M., Koppel, G., Bruns, F. R., and Simon, N. G. (2006). Orally active vasopressin $\mathrm{V} 1$ a receptor antagonist SRX251 selectively blocks aggressive behavior. Pharmacol. Biochem. Behav. 83, 169-174.

Francis, D., Diorio, J., Lui, D., and Meaney, M. J. (1999). Nongenomic transmission across generation of maternal behavior and stress responses in the rat. Science 286, 1155-1158.

Francis, D. D., Young, L. J., Meaney, M. J., and Insel, T. R. (2002). Naturally occurring differences in maternal care are associated with the expression of oxytocin and vasopressin (V1a) receptors: gender differences. J. Neuroendocrinol. 14, 349-353. 
Freeberg, T. M., Duncan, S. D., Kast, T. L., and Enstrom, D. A. (1999). Cultural influences on female mate choices; an experimental test of cowbirds, Molorthrus ater. Anim. Behav. 57, 421-426.

Galbally, M., Lewis, A. J., Ijzendoorn, M., and Permezel, M. (2011). The role of oxytocin in mother infant-relations: a systemic review of human studies. Harv. Rev. Psychiatry 19, 1-14.

Gendle, M. H., White, T. L., Strawderman, M., Mactutus, C. F., Booze, R. M., Levitsky, D. A., and Strupp, B. J. (2004). Enduring effects of prenatal cocaine exposure on selective attention and reactivity to errors: evidence from an animal model. Behav. Neurosci. 118, 290-297.

Goodwin, G. A., Heyser, C. J., Moody, C. A., Rajachandran, L., Molina, V. A., Arnold, H. M., McKinzie, D. L., Spear, N. E., and Spear, L. P. (1992). A fostering study of the effects of prenatal cocaine exposure: II. Offspring behavioral measures. Neurotoxicol. Teratol. 14, 423-432.

Greenwald, M., Chiodo, L., Hannigan, J., Sokol, R., Janisse, J., and DelaneyBlack, V. (2011). Teens with heavy prenatal cocaine exposure respond to experimental social provocation with escape not aggression. Neurotoxicol. Teratol. 33, 198-204.

Griffith, D. R., Azuma, S. D., and Chasnoff, I. J. (1994). Three-year outcome of children exposed prenatally to drugs. J. Am. Acad. Child Adolesc. Psychiatry 33, 20-27.

Hahn, M., Benno, R., Schanz, N., and Phadia, E. (2000). The effects of prenatal cocaine exposure and genotype on the ultrasonic calls of infant mice. Pharmacol. Biochem. Behav. 67, 729-738.

Hale, R. L., Randall, C. M., Becker, H. C., and Middaugh, L. D. (1992). The effect of prenatal ethanol exposure on scent marking in the C57BL/6J and $\mathrm{C} 3 \mathrm{H} / \mathrm{He}$ mouse strains. Alcohol 9, 287-292.

Haller, J., and Kruk, M. R. (2006). Normal and abnormal aggression: human disorders and novel laboratory models. Neurosci. Biobehav. Rev. 30, 292-303.

Hamilton, D. A., Akers, K. G., Rice, J. P., Johnson, T. E., CandelariaCook, F. T., Maes, L. I., Rosenberg, M., Valenzuela, C. F., and Savage, D. D. (2010). Prenatal exposure to moderate levels of ethanol alters social behavior in adult rats: relationship to structural plasticity and immediate early gene expression in frontal cortex. Behav. Brain Res. 207, 290-304.
Heinrichs, M., van Dawans, B., and Domes, G. (2009). Oxytocin, vasopressin, and human social behavior. Front. Neuroendocrinol. 30, 548-557.

Heyser, C. J., Molina, V. A., and Spear, L. P. (1992). A fostering study of the effects of prenatal cocaine exposure: I. Maternal behaviors. Neurotoxicol. Teratol. 14, 415-421.

Hill, S. Y., Lowers, L., Locke-Wellman, J., and Shen, S. A. (2000). Maternal smoking and drinking during pregnancy and the risk for child and adolescent psychiatric disorders. J. Stud. Alcohol 61, 661-668.

Howard, J., Beckwith, L., and Rodning, C. (1990). Adaptive behavior in recovering female phencyclidine/polysubstance abusers. NIDA Res. Monogr. 101, 86-95.

Huizink, A. C., and Mulder, E. J. H. (2006). Maternal smoking, drinking or cannabis use during pregnancy and neurobehavioral and cognitive functioning in human offspring. Neurosci. Biobehav. Rev. 30, 24-41.

Insel, T. (2003). Is social attachment an addictive disorder? Physiol. Behav. 79, 351-357.

Jarrett, T. M., McMurray, C. H., Walker, C. H., and Johns, J. M. (2006). Cocaine treatment alters oxytocin receptor binding but not mRNA production in postpartum rat dams. Neuropeptides 40, 161-167.

Jeremy, R. J., and Bernstein, V. J. (1984). Dyads at risk: methadonemaintained women and their fourmonth-old infants. Child Dev. 55, 1141-1154.

Johns, J. M., Elliott, D. L., Hofler, V. E., Joyner, P. W., McMurray, M. S., Jarrett, T. M., Haslup, A. M., Middleton, C. L., Elliott, J. C., and Walker, C. H. (2005). Cocaine treatment and prenatal environment interact to disrupt intergenerational maternal behavior in rats. Behav. Neurosci. 119, 1605-1618.

Johns, J. M., Lubin, D. A., Walker, C. H., Joyner, P., Middleton, C., Hofler, V., and McMurray, M. (2004). Gestational treatment with cocaine and fluoxetine alters oxytocin receptor number and binding affinity in lactating rat dams. Int. J. Dev. Neurosci. 22, 321-328.

Johns, J. M., McMurray, M. S., Hofler, V. E., Jarrett, T. M., Middleton, C. L., Elliott, D. L., Mirza, R., Haslup, A., Elliott, J. C., and Walker, C. H. (2007). Cocaine disrupts pupinduced maternal behavior in juvenile and adult rats. Neurotoxicol. Teratol. 29, 634-641.
Johns, J. M., McMurray, M. S., Joyner, P. W., Jarrett, T. M., Williams, S. K. Cox, E. T., Black, M. A., Middleton, C. L., and Walker, C. H. (2010). Effects of chronic and intermittent cocaine treatment on dominance, aggression and oxytocin levels in post-lactational rats. Psychopharmacology (Berl.) 211, 175-185.

Johns, J. M., Means, M. J., Bass, E. W., Means, L. W., Zimmerman, L. I. and McMillen, B. A. (1994a). Prenatal exposure to cocaine: effects on aggression in Sprague-Dawley rats. Dev. Psychobiol. 27, 227-239.

Johns, J. M., Noonan, L. R., Zimmerman, L. I., and Pederson, C. A. (1994b). Effects of chronic and acute cocaine treatment on the onset of maternal behavior and aggression in Sprague-Dawley rats. Behav. Neurosci. 108, 107-112.

Johns, J. M., Nelson, C. J., Meter, K. E., Lubin, D. A., Couch, C. D., Ayers, A., and Walker, C. H. (1998a). Dose-dependent effects of multiple acute cocaine injections on maternal behavior and aggression in Sprague-Dawley rats. Dev. Neurosci. 20, 525-532.

Johns, J. M., Noonan, L. R., Zimmerman, L. I., McMillen, B., Means, L. Walker, C., Lubin, D., Meter, K., Nelson, C., Pedersen, C., Mason, G., and Lauder, J. (1998b). Chronic cocaine treatment alters social/aggressive behavior in Sprague-Dawley rat dams and in their prenatally exposed offspring. Ann. N. Y. Acad. Sci. 846, 399-404.

Johns, J. M., and Noonan, L. R. (1995). Prenatal cocaine exposure affects social behavior in SpragueDawley rats. Neurotoxicol. Teratol. 17, 569-576.

Johns, J. M., Noonan, L. R., Zimmerman, L. I., Li, L., and Pedersen, C. A. (1997). Effects of short- and long-term withdrawal from gestational cocaine treatment on maternal behavior and aggression in Sprague-Dawley rats. Dev. Neurosci. 19, 368-374.

Johnson, A. L., Morrow, C. E. Accornero, V. H., Xue, L., Anthony, J. C., and Bandstra, E. S. (2002). Maternal cocaine use: estimated effects on mother-child play interactions in the preschool period. J. Dev. Behav. Pediatr. 23, 191-202.

Jones, K. L., Hoyme, H. E., Robinson, L. K., Del Campo, M., Manning, M. A., Prewitt, L. M., and Chambers, C. D. (2010). Fetal alcohol spectrum disorders: extending the range of structural defects. Am. J. Med. Genet. 152A, 2731-2735.
Kavaliers, M., Colwell, D. D., Choleris, E., Agmo, A., Muglia, L. J., Ogawa, S., and Pfaff, D. W. (2003). Impaired discrimination of and aversion to parasitized male odors by female oxytocin knockout mice. Genes Brain Behav. 2, 220-230.

Kelly, S., Day, N., and Streissguth, A. (2000). Effects of prenatal alcohol exposure on social behavior in humans and other species. Neurotoxicol. Teratol. 22, 143-149.

Kelly, S., Goodlett, C., and Hannigan, J. (2009a). Animal models of fetal alcohol spectrum disorders: impact of the social environment. Dev. Disabil. Res. Rev. 15, 200-208.

Kelly, S. J., Leggett, D. C., and Cronise, K. (2009b). Sexually dimorphic effects of alcohol exposure during development on the processing of social cues. Alcohol Alcohol. 44, 555-560.

Kelly, S. J., and Dillingham, R. R. (1994). Sexually dimorphic effects of perinatal alcohol exposure on social interactions and amygdala DNA and DOPAC concentrations. Neurotoxicol. Teratol. 16, 377-384.

Kinsley, C. H., Turco, D., Bauer, A., Beverly, M., Wellman, J., and Graham, A. L. (1994). Cocaine alters the onset and maintenance of maternal behavior in lactating rats. Pharmacol. Biochem. Behav. 47, 857-864.

Kosfeld, M., Heindrich, M., Zak, P. J., Fischbacher, U., and Fehr, E. (2005). Oxytocin increases trust in humans. Nature 423, 673-676.

Kršiak, M., Elis, J., Pöschlová, N., and Mašek, K. K. (1977). Increased aggressiveness and lower brain serotonin levels in offspring of mice given alcohol during gestation. J. Stud. Alcohol 38, 1696-1704.

Lawrence, R. C., Bonner, H. C., Newsom, R. J., and Kelly, S. J. (2008). Effects of alcohol exposure during development on play behavior and c-Fos expression in response to play behavior. Behav. Brain Res. 188, 209-218.

Lee, H.-J., Macbeth, A. H., Pagni, J. H., and Young III, W. S. (2009). Oxytocin: the great facilitator of life. Prog. Neurobiol. 88, 127-151.

Lim, M. M., and Young, L. J. (2006). Neuropeptidergic regulation of affiliative behaviour and social bonding in animals. Horm. Behav. 50, 506-517.

Linares, T. J., Singer, L. T., Kirchner, H. L., Short, E. J., Min, M. O., Hussey, P., and Minnes, S. (2006). Mental health outcomes of cocaine-exposed children at 6 years of age. J. Pediatr. Psychol. 31, 85-97. 
Lubin, D. A., Elliott, J. C., Black, M. C., and Johns, J. M. (2003). An oxytocin antagonist infused into the central nucleus of the amygdale increases maternal aggressive behavior. Behav. Neurosci. 117, 195-201.

Lubin, D. A., Meter, K. E., Walker, C. H., and Johns, J. M. (2001). Dose-related effects of chronic gestational cocaine treatment on maternal aggression in rats on postpartum days 2, 3, and 5. Prog. Neuropsychopharmacol. Biol. Psychiatry 25, 1403-1420.

Lugo, J. N., Marino, M. D., Cronise, K., and Kelly, S. J. (2003). Effects of alcohol exposure during development on social behavior in rats. Physiol. Behav. 78, 185-194.

Lugo, J. N., Marino, M. D., Gass, J. T., Wilson, M. A., and Kelly, S. J. (2006). Ethanol exposure during development reduces resident aggression and testosterone in rats. Physiol. Behav. 87, 330-337.

Magalhaes, A., Summavielle, T., Melo, P., Rosa, R., Tavares, M., and De Sousa, L. (2006). Prenatal exposure to cocaine and enriched environment. Ann. N. Y. Acad. Sci. 1074, 620-631.

Magalhaes, A., Summavielle, T., Tavares, M., and De Sousa, L. (2007). Postnatal exposure to cocaine in rats housed in an enriched environment: effects of social interactions. Hum. Exp. Toxicol. 26, 303-309.

Marino, M. D., Cronise, K., Lugo, J. N., and Kelly, S. J. (2002). Ultrasonic vocalizations and maternalinfant interactions in a rat model of fetal alcohol syndrome. Dev. Psychobiol. 41, 341-351.

Mattson, S. N., and Riley, E. P. (2000). Parent ratings of behavior in children with heavy prenatal alcohol exposure and IQ-matched controls. Alcohol. Clin. Exp. Res. 24, 226-231.

Mayes, L. C., Feldman, R., Granger, R., Haynes, O. M., Bornstein, M., and Schottenfeld, R. (1997). The effects of poly drug use with and without cocaine on mother-infant interactions at 3 and 6 months of age. Infant Behav. Dev. 20, 489-502.

McGee, C. L., and Riley, E. P. (2007). Social and behavioral functioning in individuals with prenatal alcohol exposure. Int. J. Disabil. Hum. Dev. 6, 369-382.

McGivern, R. F., Clancy, A. N., Hill, M. A., and Noble, E. P. (1984). Prenatal alcohol exposure alters adult expression of sexually dimorphic behavior in the rat. Science 224, 896-898.

McMurray, M. S., Joyner, P. W., Middleton, C. W., Jarrett, T. M., Elliott, D. L., Black, M. A., Hofler, V. E., Walker,
C. H., and Johns, J. M. (2008a). Intergenerational effects of cocaine on maternal aggressive behavior and brain oxytocin in rat dams. Stress 11 , 398-410.

McMurray, M. S., Cox, E. T., Jarrett, T. M., Williams, S. K., Walker, C. H., and Johns, J. M. (2008b). Impact of gestational cocaine treatment or prenatal cocaine exposure on early postpartum oxytocin mRNA levels and receptor binding in the rat. Neuropeptides 24, 641-652.

Meaney, M. (1989). The sexual differentiation of social play. Psychiatr. Dev. 7, 247-261.

Meaney, M. J. (2001). Maternal care, gene expression, and the transmission of individual differences in stress reactivity across generations. Annu. Rev. Neurosci. 24, 1161-1192.

Meyer, L. S., and Riley, E. P. (1986). Social play in juvenile rats prenatally exposed to alcohol. Teratology 34, 1-7.

Meyer, L. S., Sherlock, J. D., and MacDonald, N. R. (1992). Effects of prenatal cocaine on behavioral responses to a cocaine challenge on postnatal day 11. Neurotoxicol. Teratol. 14, 183-189.

Minnes, S., Singer, L. T., Kirchner, H. L., Short, E., Lewis, B., Satayathum, S., and Queh, D. (2010). The effects of prenatal cocaine exposure on problem behavior in children 4-10 years. Neurotoxicol. Teratol. 32, 443-451.

Mooney, S. M., and Varlinskaya, E. I. (2011). Acute prenatal exposure to ethanol and social behavior: effects of age, sex, and timing of exposure. Behav. Brain Res. 216, 358-364.

Nelson, C. J., Meter, K. E., Walker, C. H., Ayers, A. A., and Johns, J. M. (1998). A dose-response study of chronic cocaine on maternal behavior in rats. Neurotoxicol. Teratol. 20, 657-660.

Nelson, E., and Pankseep, J. (1996). Oxytocin mediates acquisition of maternally associated odor preference in preweanling rat pups. Behav. Neurosci. 110, 583-592.

Nephew, B. C., and Febo, M. (2010). Effect of cocaine sensitization prior to pregnancy on maternal care and aggression in the rat. Psychopharmacology 209, 127-135.

Ness, J. W., and Franchina, J. J. (1990). Effects of prenatal alcohol exposure on rat pups' ability to elicit retrieval behavior from dams. Dev. Psychobiol. 23, 85-99.

Neugebauer, N. M., Cunningham, S. T., Zhu, J., Bryant, R. I., Middleton, L. S., and Dwoskin, L. P. (2004). Effects of environmental enrichment on behavior and dopamine transporter function in medial prefrontal cortex in adult rats prenatally treated with cocaine. Brain Res. Dev. Brain Res. 153, 213-223.

Neuspiel, D. R., Hamel, S. C., Hochberg, E., Greene, J., and Campbell, D. (1991). Maternal cocaine use and infant behavior. Neurotoxicol. Teratol. 13, 229-233.

Newman, J. D. (2007). Neural circuits underlying crying and cry responding in mammals. Behav. Brain Res. 182, 155-165.

Nishimori, K., Young, L. J., Guo, Q. Wang, Z., Insel, T. R., and Matzuk, M. M. (1996). Oxytocin is required for nursing but is not essential for parturition or reproductive behavior. Proc. Natl. Acad. Sci. U.S.A. 93 , 11699-11704.

Olazabal, D. E., and Young, L. J. (2006) Species and individual differences in juvenile female alloparental care are associated with oxytocin receptor density in the striatum and the lateral septum. Horm. Behav. 49, 681-687.

Olson, H. C., Streissguth, A. P., Sampson, P. D., Barr, H. M., Bookstein, F. L., and Thiede, K. (1997). Association of prenatal alcohol exposure with behavioral and learning problems in early adolescence. J. Am. Acad. Child Adolesc. Psychiatry 36, 1187-1194.

Oro, A. S., and Dixon, S. D. (1987). Perinatal cocaine and methamphetamine exposure: maternal and neonatal correlates. J. Pediatr. 111, 571-578.

Overstreet, D. H., Moy, S. S., Lubin, D. A., Gause, L. R., Lieberman, J. A., and Johns, J. M. (2000). Enduring effects of prenatal cocaine administration on emotional behavior in rats. Physiol. Behav. 70, 149-156.

Peeke, H., Dark, K., Salamy, A., Salfi, M., and Shah, S. (1994). Cocaine exposure prebreeding to weaning: maternal and offspring effects. Pharmacol. Biochem. Behav. 48, 403-410.

Pellis, S., and Pellis, V. (1998). Play flighting of rats in comparative perspective: a schema for neurobehavioral analyses. Neurosci. Biobehav. Rev. 23, 87-101.

Ragnauth, A. K., Devidze, N., Moy, V., Finley, K., Goodwillis, A., Kow, L. M., Muglia, L. J., and Pfaff, D. W. (2005). Female oxytocin geneknockout mice, in a semi-natural environment, display exaggerated aggressive behavior. Genes Brain Behav. 4, 229-239.

Raum, W. J., McGivern, R. F., Peterson, M. A., Shryne, J. H., and Gorski, R. A. (1990). Prenatal inhibition of hypothalamic sex steroid uptake by cocaine: effects on neurobehavioral sexual differentiation in male rats. Brain Res. Dev. Brain Res. 53, 236.

Richardson, G. A., Goldschmidt, L., and Willford, J. (2009). Continued effects of prenatal cocaine use: preschool development. Neurotoxicol. Teratol. 31, 325-333.

Ripabelli, G., Cimmino, L., and Grasso, G. M. (2006). Alcohol consumption, pregnancy and fetal alcohol syndrome: implications in public health and preventive strategies. Ann. Ig. 18, 391-406.

Rodning, C., Beckwith, L., and Howard, J. (1989). Prenatal exposure to drugs and its influence on attachment. Ann. N. Y. Acad. Sci. 562, 352-364.

Ross, H. E., and Young, L. J. (2009). Oxytocin and the neural mechanisms regulating social cognition and affiliative behavior. Front. Neuroendocrinol. 30, 534-547.

Royalty, J. (1990). Effects of prenatal ethanol exposure on juvenile playfighting and postpubertal aggression in rats. Psychol. Rep. 66, 551-560.

Savaskan, E., Ehrhardt, R., Schulz, A., Walter, M., and Schachinger, H. (2008). Post-learning intranasal oxytocin modulates human memory for facial identity. Psychoneuroendrocrinology 33, 368-374.

Sayal, K., Heron, J., Golding, J., and Emond, A. (2007). Prenatal alcohol exposure and gender differences in childhood mental health problems: a longitudinal populationbased study. Pediatrics 119, E426E434.

Schuckit, M. A., Smith, T. L., Barnow, S., Preuss, U., Luczak, S., and Radziminski, S. (2003). Correlates of externalizing symptoms in children from families of alcoholics and controls. Alcohol Alcohol. 38, 559-567.

Sekiguchi, R., Wolterink, G., and van Ree, J. M. (1991). Analysis of the influence of vasopressin neuropeptides on social recognition of rats. Eur. Neuropsychopharmacol. 1, 123-126.

Sobrian, S., Ali, S., Slikker, S. Jr., and Holson, R. (1995). Interactive effects of prenatal cocaine and nicotine exposure on maternal toxicity, postnatal development, and behavior in the rat. Mol. Neurobiol. 11, 121-143. Sobrian, S. K., Burton, L. E., Robinson, L. E., Ashe, W. K., James, H., Stokes, D. L., and Turner, L. M. (1990). Neurobehavioral and immunological effects of prenatal cocaine exposure in rat. Pharmacol. Biochem. Behav. 35, 617-629. 
Sood, B., Bailey, B., Covington, C., Sokol, R., Ager, J., Janisse, J., Hannigan, J., and Delaney-Black, V. (2005). Gender and alcohol moderate caregiver reported child behavior after prenatal cocaine. Neurotoxicol. Teratol. 27, 191-201.

Sood, B., Delaney-Black, V., Covington, C., Nordstrom-Klee, B., Ager, J., Templin, T., Janisse, J., Martier, S., and Sokol, R. J. (2001). Prenatal alcohol exposure and childhood behavior at age 6 to 7 years: I. Dose-response effect. Pediatrics 108, e34.

Sousa, N., Almeida, O. F. X., and Wotjak, C. T. (2006). A hitchhiker's guide to behavioral analysis in laboratory rodents. Genes Brain Behav. 5(Suppl. 2), 5-24.

Strathearn, L., Li, J., Fonagy, P., and Montague, P. R. (2008). What's in a smile? Maternal brain responses to infant facial cues. Pediatrics 122, 40-51.

Strathearn, L., and Mayes, L. (2010). Cocaine addiction in mothers: potential effects on maternal care and infant development. Ann. N. Y. Acad. Sci. 1187, 172-183.

Tankayanagi, Y., Yoshida, M., Bielsky, I. F., Ross, H. E., Kawamata, M., Onaka, T., Yanagisawa, T., Kimura, T., Matzuk, M. M., Young, L. J., and Nishimori, K. (2005). Pervasive social deficits, but normal parturition, in oxytocin receptor-deficient mice. Proc. Natl. Acad. Sci. U.S.A. 16096-16101.

Tattoli, M., Cagiano, R., Gaetani, S., Ghiglieri, V., Giustino, A., Mereu, G., Trabace, L., and Cuomo, V. (2001). Neurofunctional effects of developmental alcohol exposure in alcohol-preferring and alcohol-nonpreferring rats. Neuropsychopharmacology 691-705.

Thompson, R. R., George, K., Walton, J. C., Orr, S. P., and Benson, J. (2006). Sex-specific influences of vasopressin on human social communications. Proc. Natl. Acad. Sci. U.S.A. 103, 7889-7894

Thor, D., and Holloway, W. (1984). Social play in juvenile rats: a decade of methodological and experimental research. Neurosci. Biobehav. Rev. 8, 455-464.

Tonkiss, J., Shumsky, J., Shultz, P., Almeida, S., and Galler, J. (1995). Prenatal cocaine but not prenatal malnutrition affects foster motherpup interactions in rats. Neurotoxicol. Teratol. 17, 601-608.

Trezza, V., Baarendse, P. J., and Vanderschuren, L. J. (2010). The pleasures of play: pharmacological insights into social reward mechanisms. Trends Pharmacol. Sci. 31, 463-469.

Tronick, E. Z., and Beeghly, M. (1999). Prenatal cocaine exposure, child development, and the compromising effects of cumulative risk. Clin. Perinatol. 26,151-171.

Tronick, E. Z., and Cohn, J. F. (1989). Infant-mother face-to-face interaction: age and gender differences in coordination and the incidence of miscoordination. Child Dev. 60, 85-92.

Tronick, E. Z., Messinger, D. S., Weinberg, M. K., Lester, B. M., Lagasse, L., Seifer, R., Bauer, C. R., Shankaran, S., Bada, H., Wright, L. L., Poole, K., and Liu, J. (2005). Cocaine exposure is associated with subtle compromises of infants' and mothers' socialemotional behavior and dyadic features of their interaction in the faceto-face still-face paradigm. Dev. Psychol. 41, 711-722.

van Gelder, M. M., Reefhuis, J., Caton, A. R., Werler, M. M., Druschel, C. M., and Roeleveld, N. (2010). Characteristics of pregnant illicit drug users and associations between cannabis use and perinatal outcome in a population-based study. Drug Alcohol Depend. 109, 243-247.

van Leengoed, E., Kerker, E., and Swanson, H. H. (1987). Inhibition of postpartum maternal behavior in the rat by injecting an oxytocin antagonist into the cerebral ventricles. $J$. Endocrinol. 112, 275-282.

Vernotica, E. M., Lisciotto, C. A., Rosenblatt, J. S., and Morrell, J. I. (1996). Cocaine transiently impairs maternal behavior in the rat. Behav. Neurosci. 110, 315-323.

Vorhees, C. V., Inman-Wood, S. L., Morford, L. L., Reed, T. M., Moran,
M. S., Pu, C., and Cappon, G. D. (2000). Evaluation of neonatal exposure to cocaine on learning, activity, startle, scent marking, immobility, and plasma cocaine concentrations. Neurotoxicol. Teratol. 22, 255-265.

Walum, H., Westberg, L., Henningsson, S., Neiderhiser, J. M., Reiss, D., Igl, W., Ganiban, J. M., Spotts, E. L. Pederson, N. L., Eriksson, E., and Lichtenstein, P. (2008). Genetic variation in the vasopressin receptor la gene (AVPR1A) associates with pair-bonding behavior in humans. Proc. Natl. Acad. Sci. U.S.A. 105, 14153-14156.

Wasserman, D. R., and Leventhal, J. M. (1993). Mistreatment of children born to cocaine-dependent mothers. Am. J. Dis. Child. 147, 1324-1328.

Wellmann, K., Lewis, B., and Barron, S. (2010). Agmatine reduces ultrasonic vocalization deficits in female rat pups exposed neonatally to ethanol. Neurotoxicol. Teratol. 32, 158-163.

Wersinger, S. R., Kelliher, K. R., Zufall, F., Lolait, S. J., O'Carroll, A. M., and Young, W. S. (2004). Socail motivation is reduced in vasopressin $1 \mathrm{~b}$ receptor null mice despite normal performance in an olfactory discrimination task. Horm. Behav. 46, 638-645.

Wilson, J. H., Kelly, S. J., and Wilson, M. A. (1996). Early postnatal alcohol exposure in rats: maternal behavior and estradiol levels. Physiol. Behav. 59, 287-293.

Winslow, J. T., Hearns, E. F., Ferguson, J., Young, L. J., Matzuk, M. M., and Insel, T. R. (2000). Infant vocalization, adult aggression, and fear behavior of an oxytocin null mutant mouse. Horm. Behav. 37, 145-155.

Winslow, J. T., and Insel, T. R. (2002). The social deficits of the oxytocin knockout mouse. Neuropeptides 36 221-229.

Wolf, J. B., Leamy, L. J., Roseman, C. C., and Cheverud, J. M. (2011). Disentangling prenatal and postnatal maternal genetic effects reveals persistent prenatal effects on offspring growth in mice. Genetics 189 , 1069-1082.

Wood, R. D., Bannoura, M. D., and Johanson, I. B. (1994). Prenatal cocaine exposure: effects on play behavior in the juvenile rat. Neurotoxicol. Teratol. 16, 139-144.

Wood, R. D., Molina, V. A., Wagner, J. M., and Spear, L. P. (1995) Play behavior and stress responsivity in periadolescent offspring exposed prenatally to cocaine. Pharmacol. Biochem. Behav. 52, 367-374.

Wood, R. D., and Spear, L. P. (1998). Prenatal cocaine alters social competition of infant, adolescent and adult rats. Behav. Neurosci. 112, 419-431.

Young, W. S. III, Shepard, E., Amico, J., Hennighausen, L., Wagner, K. U., LaMarca, M. E., McKinney, C., and Ginns, E. I. (1996). Deficiency in mouse oxytocin prevents milk ejection, but not fertility or parturition. J. Neuroendocrinol. 8, 847-853.

Young, L. J., and Wang, Z. (2004). The neurobiology of pair-bonding. Nature Neurosci. 7, 1048-1054.

Conflict of Interest Statement: The authors declare that the research was conducted in the absence of any commercial or financial relationships that could be construed as a potential conflict of interest.

Received: 18 April 2011; accepted: 11 November 2011; published online: 30 November 2011.

Citation: Sobrian SK and Holson RR (2011) Social behavior of offspring following prenatal cocaine exposure in rodents: a comparison with prenatal alcohol. Front. Psychiatry 2:66. doi: 10.3389/fpsyt.2011.00066

This article was submitted to Frontiers in Child and Neurodevelopmental Psychiatry, a specialty of Frontiers in Psychiatry. Copyright (c) 2011 Sobrian and Holson. This is an open-access article distributed under the terms of the Creative Commons Attribution Non Commercial License, which permits use, distribution, and reproduction in other forums, provided the original authors and source are credited. 